Article

\title{
Impact of the Drying Temperature and Grinding Technique on Biomass Grindability
}

\author{
Marcin Jewiarz $^{1, *\left(\mathbb{C}, \text { Marek Wróbel }^{1}\left(\mathbb{D}, \text { Krzysztof Mudryk }^{1}(\mathbb{D} \text { and Szymon Szufa }\right.\right.}{ }^{2} \mathbb{C}$ \\ 1 Department of Mechanical Engineering and Agrophysics, University of Agriculture in Krakow, \\ 30-149 Kraków, Poland; marek.wrobel@urk.edu.pl (M.W.); krzysztof.mudryk@urk.edu.pl (K.M.) \\ 2 Department of Environmental Engineering, Lodz University of Technology, 90-924 Lodz, Poland; \\ szymon.szufa@p.lodz.pl \\ * Correspondence: marcin.jewiarz@urk.edu.pl; Tel.: +48-12-6624643
}

Received: 10 June 2020; Accepted: 28 June 2020; Published: 2 July 2020

\begin{abstract}
The process of biomass compaction depends on many factors, related to material and process. One of the most important is the proper fragmentation of the raw material. In most cases, more fragmented raw material makes it easier to achieve the desired quality parameters of pellets or briquettes. While the chipping of biomass prefers moist materials, for grinding, the material needs to be dried. As drying temperature changes the properties of the material, these may affect the grinding process. The aim of this work was to determine the influence of the drying temperature of biomass raw material in the range of $60-140{ }^{\circ} \mathrm{C}$ on the biomass grindability. To only determine this effect, without the influence of moisture, grinding was carried out on the material in a dry state. The research was carried out on a mill with a knife and hammer grinding system, which is the most popular in the fragmentation of biomass. The analysis of particle size distribution and bulk density of the obtained material was carried out. The energy demand for the grinding process was determined and it was shown that drying temperature, grinding system, and mainly type of biomass affects the grindability.
\end{abstract}

Keywords: bulk density; particle size distribution; energy demand; Scots pine; European beech; Cup plant; Giant miscanthus

\section{Introduction}

Biomass, regardless of origin and source (woody, herbaceous, fruit or water) [1], from a chemical point of view, consists of three main components: cellulose, hemicellulose, and lignin. Thus, this kind of biomass is called lignocellulose biomass [2,3], and contains about $50 \%$ of carbon and about $6-8 \%$ hydrogen [4-6]. This is the main reason why it is mainly used as a biofuel [7]. From the point of view of the energy use of biomass, most of the energy accumulated in a given biomass is found in cellulose, hemicellulose, and lignin. Separately, the heat of combustion for cellulose and hemicellulose are similar: 17.6 and $17.9 \mathrm{MJ} \cdot \mathrm{kg}^{-1}$ [4], respectively. Lignin heat of combustion is higher and depends on the type of biomass: lignins from spruce and beech, but also from olive pomace, walnut, and hazelnut shells, have $27-28 \mathrm{MJ} \cdot \mathrm{kg}^{-1}[8,9]$. Therefore, the biomass heat of combustion is determined by the proportion of lignin in relation to holocellulose, however, despite the different levels of lignin, cellulose, and hemicellulose in biomass [10-13], the biomass heat of combustion has a narrow range of $18-22 \mathrm{MJ} \cdot \mathrm{kg}^{-1}[14,15]$.

This energy homogeneity means that biomass from a wide range of sources is taken into account as raw material for the production of solid biofuels. These include coniferous and deciduous woods [16-18], different species of grasses [19-21], and dicotyledonous perennials [22-24] as well as straw. Recently, more popular are shells, stones, husks, pomaces [25-27], and aquatic biomass [28,29]. 
Therefore, biomass as a raw material for the production of solid biofuels is characterized by a very high diversity of physical properties such as moisture content just after harvest, specific and bulk density, or form. This heterogeneous raw material must be processed into a product that has a uniform quality. Only standardized quality fuel allows for the combustion process to be properly conducted [30] and allows for automation of the feeding and burning process, which is a standard in current modern heating systems [31].

In order to obtain a high quality final product in the form of pellets or briquettes, it is very important that the preparation of the raw material is carried out properly. The biomass during harvest usually has two disadvantages: high moisture content (MC) and a low degree of fragmentation (shoots, chips, chipped straw, etc.). For example, the wood moisture content of different cultivars of poplar vary from $54 \%$ to $62 \%$ [32], willow from $48-59 \%$ [33], MC of lawn grass was 39\% [34], miscanthus was $22.5 \%$ [35], perennials like Cup plant, Virginia mallow, or willowleaf sunflower of 22, 26, and 38\%, respectively [36], cherry stones up 28.6 to $36.5 \%$ [37], and hazelnut shells have on average 6\% [38]. Biomass raw materials have low specific densities, grasses about 40 to $150 \mathrm{~kg} / \mathrm{m}^{3}$, and woodchips about 150 to $200 \mathrm{~kg} / \mathrm{m}^{3}[39,40]$.

These properties of the raw material do not allow for its direct processing in a pressure agglomeration into pellets or briquettes. Two stages are therefore necessary to prepare the raw material properly: drying and grinding afterward. The order of these steps is important because the grinding process is more efficient when the material is dry, where a humidity of less than $15 \%$ is recommended [41,42].

The drying process is designed to bring the material to the technological moisture content. This value depends on the type of raw material and parameters of the densification process and should be between $6-17 \%$ [40,43-45]. However, most often, it is considered that the optimum MC for the pressure process of a biomass agglomeration is $12 \%$ [46,47], or even $10 \%$ [48]. The drying process is carried out by temperature from a wide range $40-200{ }^{\circ} \mathrm{C}$ or even more [49-52] however, due to the low ignition temperature of biomass, which on average is $250^{\circ} \mathrm{C}$, with great caution [53]. Biomass components, due the temperature, can be transformed [54-56]. High temperature in the $150-300{ }^{\circ} \mathrm{C}$ range used in the torrefaction process improves the raw material grindability [57-60]. An open question exists whether this effect is caused by drying in the lower temperature range up to $150^{\circ} \mathrm{C}$.

The grinding process is designed to prepare the raw material with the appropriate degree of fragmentation and particle composition for the process of pressure agglomeration. In this process, the particles of ground raw material, due the pressure, merge to form an agglomerate. By reducing the volume of the compacted material, in the first stage, the material particles are rearranged and aligned without changing their shape and size and the number of contact points between the material particles increases. In the second stage, the pressure increases, causing particle deformation and size change. The brittle particles break, which results in an increase in the number of contact points and the elastic particles deform, as a result of which the contact points turn into contact surfaces [39,61-63].

The pressure compaction of the ground, granular material causes particle movement and deformation. This is also accompanied by friction, which increases the temperature, making the particles more plastic [64-66]. As a result, in the initial phase, the particles approach each other and meet at contact points which, after deformation, form contact surfaces. All mechanisms of particle connection occur precisely at the contact points and surfaces between the particles $[67,68]$. Therefore, from the agglomeration point of view, it is extremely important to maximize the number of particle contact points. This maximization takes place during the agglomeration process, but it can also be increased by the appropriate preparation of the raw material, the appropriate degree of fragmentation and particle size distribution of the obtained mixture of particles. The raw material degree of fragmentation is most often determined by the mesh size of the screen used in the grinding device. This size determines the maximum particle size, but smaller particles are also produced during grinding. The share of individual size fractions of particles in the whole ground material is defined as the particle size 
distribution (PSD). The biomass for the production of solid biofuels, it is tested based on the EN ISO 17827 standard [69]. Commonly, it is presented in the form of the percentage share of each dimensional fraction in the whole bed or in the form of the cumulative distribution curve of particle size, the sum of dimensional fractions remaining on subsequent sieves. The second method allows for a simple comparison of the ground materials and an indication of which of them has a higher share of fine fractions, and thus which of them have been grounded more. To complete the information about particle size distribution, the median value of grain size $d_{50}$ is calculated and defined as the sample particle size, which divides the cumulative distribution curve into two equal parts.

Particle size distribution depends on the origin of the raw material $[48,70,71]$ as well as on the grinding technique [44,72]. In their research, Kirsten et al. ground hay on a cutting, impact, and hammer mill equipped with a $4 \mathrm{~mm}$ diameter sieve. In addition, the mills worked with and without an aspiration system to improve material flow through the mill. In each grinding variant, the produced mixture had a different PSD [72]. Puig-Arnavat et al. ground six types of biomass on a mill equipped with a $4 \mathrm{~mm}$ sieve, and despite the same grinding process conditions, each material had a different cumulative article size distribution (cPSD) [48].

The raw material degree of fragmentation has a direct and significant impact on what is produced from the granulate quality. In general, with the increase in raw material fragmentation and the following changes in PSD (decrease in the value of $d_{50}$ ), the granules' density and mechanical durability increases. This trend is confirmed both by our own research $[73,74]$ and also by other authors [75-81].

It is recommended that the material for pellet production should be ground using a maximum of $4 \mathrm{~mm}$ mesh screen $[45,82,83]$, whereas the recommended median particle size $d_{50}$ to obtain a high pellet strength is $0.6-0.8 \mathrm{~mm}$ [84], 0.5-0.7 $\mathrm{mm}$ [85], or even $0.2-0.4 \mathrm{~mm}$ [77].

The results of other studies [72,75] also indicates that not always a high degree of fragmentation guarantees higher quality granules. Bergstrom et al. noted that a material consisting of $100 \%$ of particles not exceeding $1 \mathrm{~mm}$ did not guarantee a granulate with a higher strength compared to a granulate made from a material where the main particle size was $4 \mathrm{~mm}$ and less. This is due to the bulk density (BD) of the material. Deposits made of particles with a narrow dimensional range are characterized by a lower value of $\mathrm{BD}$ in comparison with those with a wider dimensional range. Therefore, the criterion of proper grindability may be not only the PSD, but also a high value of BD of the obtained mixture [86]. Biomass grindability is a relatively new issue. To determine the grindability of torrefied biomass, methods used for coal are often adapted, for example, the Hardgrove Grindability Index (HGI) or Bond Work Index (BWI) [87-90]. However, even after their modification by grinding a $50 \mathrm{~cm}^{3}$ sample instead of a $50 \mathrm{~g}$ sample [87], it is claimed that these indicators are not sufficiently accurate, especially when applied to untreated biomass [88]. Grindability is also described as the degree of change in PSD, $d_{50}$, or the width of the particle size distribution called SPAN. These ratings provide for the highest possible fragmentation and unification of the particle, thus minimizing $d_{50}$ and SPAN $[87,91-94]$. Such an assumption is rational from the point of view of the combustion process of pulverized fuel, but not necessary from the point of view of the compaction process. In fact, there is no good indicator of the grindability for biomass intended for the production of solid biofuels $[87,88]$.

The grindability is influenced by both the type of material and the way the grinding process is conducted. However, there have been no studies on whether and how the drying process temperature affects grindability including are there any changes in the material, which at the grinding stage will be reflected in changes in the obtained material particle size composition or bulk density, and the effort required for the process. If the drying process allows for better grinding, it would be very important information in the development of dedicated process technologies for the production of solid biofuels from various types of biomass. Data on raw material parameters determine the selection of technological parameters of the designed granulate production lines [95-98]. The aim of this study was to investigate the effect of drying temperature on the selected biomass grindability and the energy input for the process. Biomass chosen in this study represents a wide range of raw materials used for the production of solid biofuels (i.e., woody and herbaceous biomass). 


\section{Materials and Methods}

\subsection{Materials}

Biomass for energy purposes can have different origins and sources [1]. Due to the availability of this material, the most common energy raw material in Poland is woody biomass. However, the increasing demand for biomass has created the need to search for new sources of raw material for the production of solid biofuels. Therefore, short rotation coppices (herbaceous biomass) have become more and more popular in the energy mix. Four plant species with significantly different physical properties were used: Scots pine Pinus sylvestris L. (soft wood) and European beech Fagus sylvatica L. (hard wood) as representatives of woody biomass, and Cup plant Silphium perfoliatum L. (dicotyledonous perennial) with Giant miscanthus Miscanthus $\times$ giganteus Greef et Deu (perenial grass) as a herbaceous biomass.

All material was collected after the 2019 growth season, the woody biomass was debarked, then all samples was chipped.

\subsection{Drying}

A sieve shaker (LPzE-4e, Morek Multiserw, Marcyporęba, Poland) with a $400 \mathrm{~mm}$ diameter analytical sieve set with hole sizes of 16 and $8 \mathrm{~mm}$ (Morek Multiserw, Marcyporęba, Poland) was used to prepare the sample before drying, which allowed for a geometrically uniform sample. Dried was the particle size fraction that passed through the $16 \mathrm{~mm}$ hole size sieve and remained in the $8 \mathrm{~mm}$ hole size sieve ( $A_{1}$ sieve class in which the particle diameter $d$ is in the range from 8 to $16 \mathrm{~mm}$ ). Samples of each investigated biomass were divided into three subsamples and dried at the temperatures of 60 , 100 , and $140^{\circ} \mathrm{C}$ to the dry state. The drying process was conducted in a laboratory dryer (SLW 115, Pol-Eko, Wodzisław Ślaski, Poland). To determine this effect on grindability, without the influence of moisture content, further experiments were carried out on the material in a dry state.

\subsection{Solid Density of Samples}

After drying and cooling the samples, their solid density DE was measured using a quasi-fluid pycnometer (GeoPyc 1360, Micromeritics Instrument Corp., Norcross, GA, USA), the details of which are described in previous work [32]. The measurement was aimed at determining whether the drying temperature affects the $\mathrm{DE}$ value. The received results, together with the bulk density $\mathrm{BD}$, were used to calculate the bed packing density $\varphi$.

\subsection{Grinding-Preliminary Stage}

The grinding process was carried out with a preliminary and main stage. First, sieve class $\mathrm{A}_{1}$ of all materials was ground in a knife mill equipped with a sieve with a $6 \mathrm{~mm}$ hole diameter (Testchem LMN-100, Pszów, Poland).

For each gained material, a particle analysis was performed. The determination was carried out in accordance with EN ISO 17827-2 [99]. Each sample was sieved using a sieve set with hole size 6; $3.15 ; 2 ; 1.41 ; 0.5 ; 0.25 \mathrm{~mm}$, and shaker (LPzE-4e, Morek Multiserw, Marcyporęba, Poland). Finally the material samples were divided into eight sieve classes (Table 1).

Table 1. Sieve classes of material samples.

\begin{tabular}{ccccccccc}
\hline Sieve Classes $(\mathbf{m m})$ & $\mathbf{B}_{\mathbf{1}}: \mathbf{0 . 2 5}$ & $\mathbf{B}_{\mathbf{2}}: \mathbf{0 . 5}$ & $\mathbf{B}_{3}: \mathbf{1}$ & $\mathbf{B}_{\mathbf{4}}: \mathbf{1 . 4}$ & $\mathbf{B}_{5}: \mathbf{2}$ & $\mathbf{B}_{\mathbf{6}}: \mathbf{3 . 1 5}$ & $\mathbf{B}_{7}: \mathbf{6}$ & $\mathbf{B}_{8}:+\mathbf{6}$ \\
\hline Particle Diameter $\mathrm{d}(\mathrm{mm})$ & $\mathrm{d} \leq 0.25$ & $0.25<\mathrm{d} \leq 0.5$ & $0.5<\mathrm{d} \leq 1$ & $1<\mathrm{d} \leq 1.4$ & $1.4<\mathrm{d} \leq 2$ & $2<\mathrm{d} \leq 3.15$ & $3.15<\mathrm{d} \leq 6$ & $\mathrm{~d}>6$ \\
\hline
\end{tabular}

The samples' particle size distribution (PSD) varied significantly (Figure 1). This is mainly due to the different shapes of the ground fragments of steams (Miscanthus and Silphium) and chips (woody biomass). Before the main grinding stage, the PSD of all samples was standardized. This allowed us to avoid the influence of different input PSD on the output PSD. 


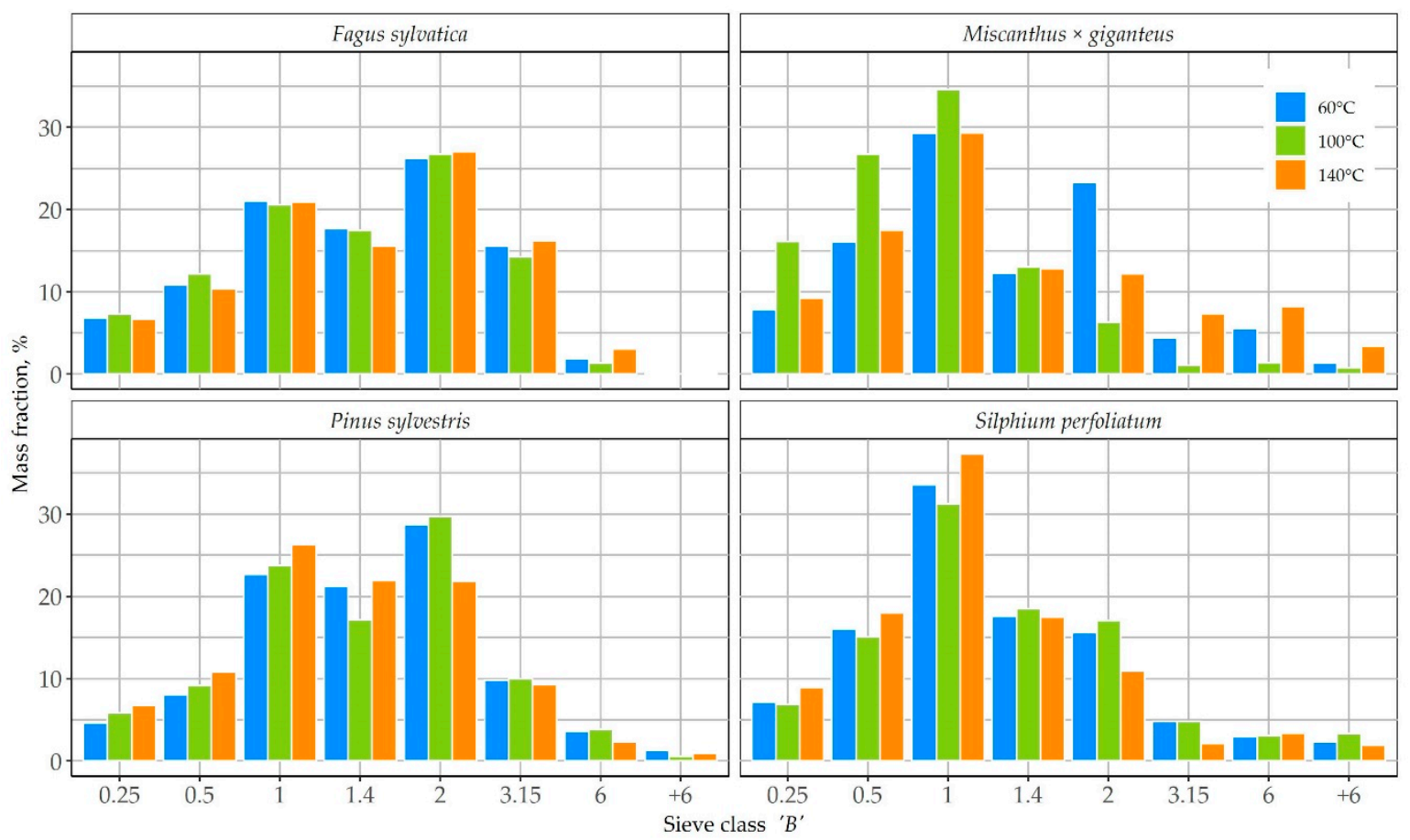

Figure 1. The samples' particle size distribution after the preliminary grinding stage.

The standardized PSD included fractions $\mathrm{B}_{3}, \mathrm{~B}_{4}$, and $\mathrm{B}_{5}$ that had the largest share in the PSD of individual samples, especially woody biomass samples. The $\mathrm{B}_{6}, \mathrm{~B}_{7}$, and $\mathrm{B}_{8}$ fractions were omitted to prevent the large particles from causing disruption during the main grinding stage. Additionally, fractions $B_{1}$ and $B_{2}$ were omitted to ensure that fine particles were not only ballast during grinding. Table 2 contains the standardized PSD of all samples.

Table 2. Standardized particle size distribution of the samples.

\begin{tabular}{ccccc}
\hline Sieve Classes $(\mathbf{m m})$ & $\mathbf{B}_{\mathbf{3}}: \mathbf{1}$ & $\mathbf{B}_{\mathbf{4}}: \mathbf{1 . 4}$ & $\mathbf{B}_{\mathbf{5}}: \mathbf{2}$ & $\boldsymbol{d}_{\mathbf{5 0}}(\mathbf{m m})$ \\
\hline Share $(\%)$ & 43 & 26 & 31 & 1.09 \\
\hline
\end{tabular}

Finally, samples were made by mixing the $B_{3}-B_{5}$ fractions in appropriate proportions and their bulk density (BD) was determined according to the current version of the EN ISO 17,828 standard [100].

\subsection{Grinding-Main Stage}

All prepared samples were ground in a mill (PX-MFC 90D Polymix, Kinematika, Luzern, Switzerland) to obtain particles with a size of $<2 \mathrm{~mm}$. Two grinding technique was investigated: hammer and knife grinding (Figure 2)

During the grinding process, the device was connected to the network through the ND1 energy quality measurement system (Lumel, Zielona Góra, Poland). The device measures the changes in the electric current value. Based on this, knowing the registration interval, the total energy consumption can be calculated. The volume of material ground during a single grinding cycle was $250 \mathrm{~cm}^{3}$. The sample to the mill was fed periodically in the amount of $25 \mathrm{~cm}^{3}$. The whole procedure was performed three times to eliminate the coarse measurement errors. Before milling, the idle energy demand needs to be measured. This is the energy needed to run the grinder without material in the chamber. As usual, we measured the electric current for $60 \mathrm{~s}$ work time of the empty grinder. We measured this parameter for both grinding systems. An average value was the reference point for net energy demand estimation, and it was also the point at which we stopped milling. 


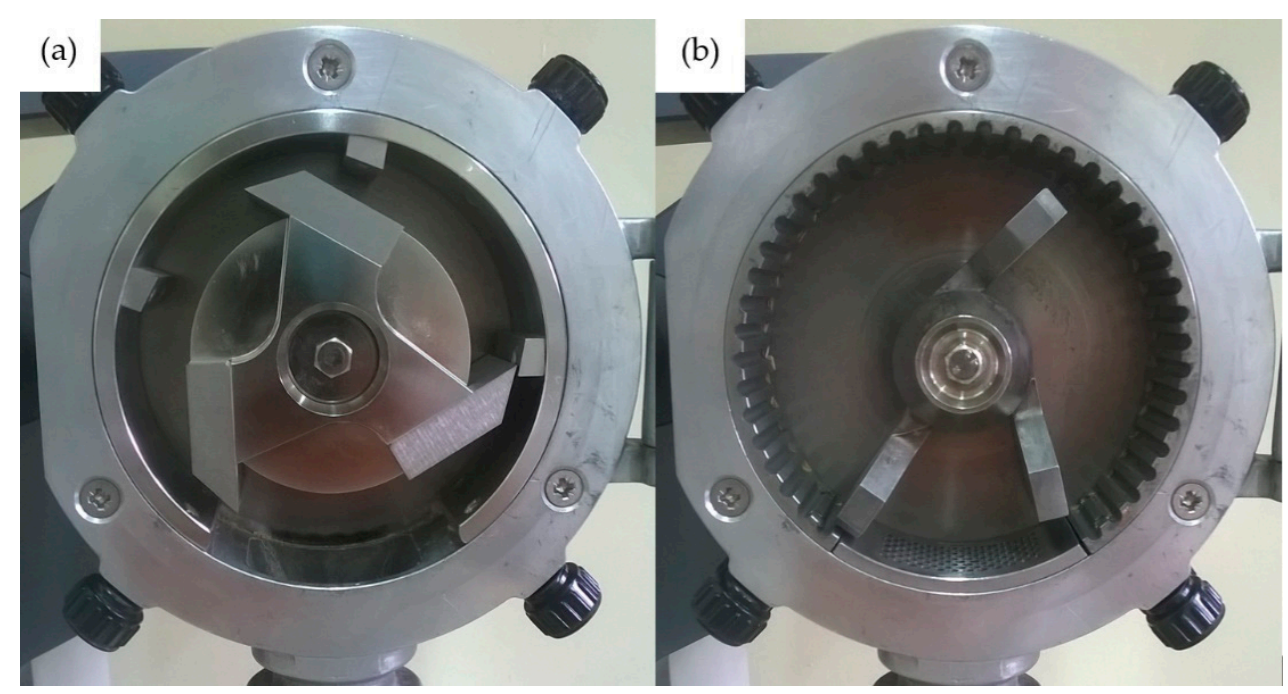

Figure 2. Mill PX-MFC 90D Polymix equipped with a knife (a) and hammer (b) grinding system.

The specific net energy demands $\left(E_{n e t . s}\right)$ were calculated according to the mass of the sample that was milled.

$$
E_{\text {net. }}=\frac{E_{\text {net }}}{m_{i}}
$$

where $E_{\text {net }}$ is net energy demand and $m_{I}$ is sample mass.

Usage of different materials requires special quantities to compare the energy demands. In the case of grinding, it is useful to know how much of the energy is used to produce the most important fraction. In our case, one very interesting parameter would be the grinding criterion first introduced by Sokolowski $[92,101]$, which was initially used for flour production processes. This quantity is described in Equation (2)

$$
G_{0.25}=\frac{E_{n e t . s}}{S_{0.25}}
$$

where $G_{0.25}$ is the grinding criterion and $S_{0.25}$ is the cumulated share of $C_{0.25}$ fraction.

After grinding, the samples' PSD was again determined. This time, the samples were divided into seven sieve classes: $C_{1}: 0.1$ is the particle diameter $\mathrm{d} \leq 0.1 \mathrm{~mm} ; C_{2}: 0.25$ is the particle diameter between $0.1<\mathrm{d} \leq 0.25 \mathrm{~mm} ; C_{3}: 0.5-0.25<\mathrm{d} \leq 0.5 \mathrm{~mm} ; C_{4}: 0.71-0.5<\mathrm{d} \leq 0.71 \mathrm{~mm} ; C_{5}: 1-0.71<\mathrm{d} \leq 1 \mathrm{~mm}$; $C_{6}: 1.4-1<\mathrm{d} \leq 1.4 \mathrm{~mm}$; and $C_{7}: 2-1.4<\mathrm{d} \leq 2 \mathrm{~mm}$. Based on the received data, the cumulative PSD of the samples was determined. Then, the median value of particle size $d_{50}$, which clearly shows a difference between samples fragmentation, was determined from Equation (3).

$$
d_{50}=C_{<50}+\left(50-S_{<50}\right) \cdot \frac{C_{>50}-C_{<50}}{S_{>50}-S_{<50}}
$$

where $S_{<50}$ is the highest cumulated share of the fraction not exceeding $50 \% ; S_{>50}$ is the lowest cumulated share of fraction, exceeding $50 \% ; C_{<50}$ is the sieve class corresponding to $S_{<50}$; and $C_{>50}$ is the sieve class corresponding to $S_{>50}$.

An important indicator of the homogeneity of the mixtures is the width of the distribution SPAN and dimensionless relative SPAN [102,103]. SPAN is defined as the difference between $d_{90}$ and $d_{10}$, where $d_{90}$ means that $90 \%$ of the mixture particle have a diameter equal or less than $d_{90}$, respectively; and $d_{10}$ is the $10 \%$ of particles that have a diameter equal or below $d_{10}$. Relative SPAN was calculated from Equation (4):

$$
\operatorname{rSPAN}=\frac{d_{90}-d_{10}}{d_{50}}
$$


After grinding, the BD of samples was also determined. Based on the results of measurements of DE and BD from Equation (5), the bed packing density $\varphi$ was determined for samples before and after the main grinding stage.

$$
\varphi=\frac{\mathrm{BD}}{\mathrm{DE}}
$$

where BD is the sample bulk density $\left[\mathrm{kg} / \mathrm{m}^{3}\right]$ and DE is the solid density of the sample $\left[\mathrm{kg} / \mathrm{m}^{3}\right]$.

\section{Results and Discussion}

\subsection{Grindability in Aspect of Particle Size Distribution Changes}

Figures 3 and 4 show the cumulative PSD (cPSD) for knife and hammer system, respectively. Horizontal red and seledite lines indicate threshold levels $d_{10}, d_{50}$, and $d_{90}$. In the case of the knife system, the greatest differences in cumulative curves are for Pinus. The cross-section with threshold lines indicate a decrease in $d_{10}, d_{50}$, and $d_{90}$ as the drying temperature of the raw material increases. The curve moves to the left, which means that the material fragmentation increases. A similar trend was observed for Silphium for $d_{10}$ and $d_{50}$. The values of $d_{90}$ were similar for each temperature variant. The opposite trend was observed for Miscanthus. The $d_{90}$ value dropped as the drying temperature of the raw material increased. In the case of Fagus, the values $d_{10}, d_{50}$, and $d_{90}$ changed slightly.

In the case of the hammer system, for most materials, a slightly different course of changes was observed (Figure 4). Accumulated curves of Pinus and Silphium showed minor changes compared to those milled with the knife system. Fagus, as for the knife system, did not show grindability dependence on drying temperature. The most significant changes for all d were observed for Miscanthus. Observed changes in cPSD indicate that an increase in drying temperature affects noticeable grindability. This is in line with the common trend observed for biomass $[87,89,91]$. This is probably because a drying temperature above $100{ }^{\circ} \mathrm{C}$ causes structural changes of biomass, which makes it more fragile.

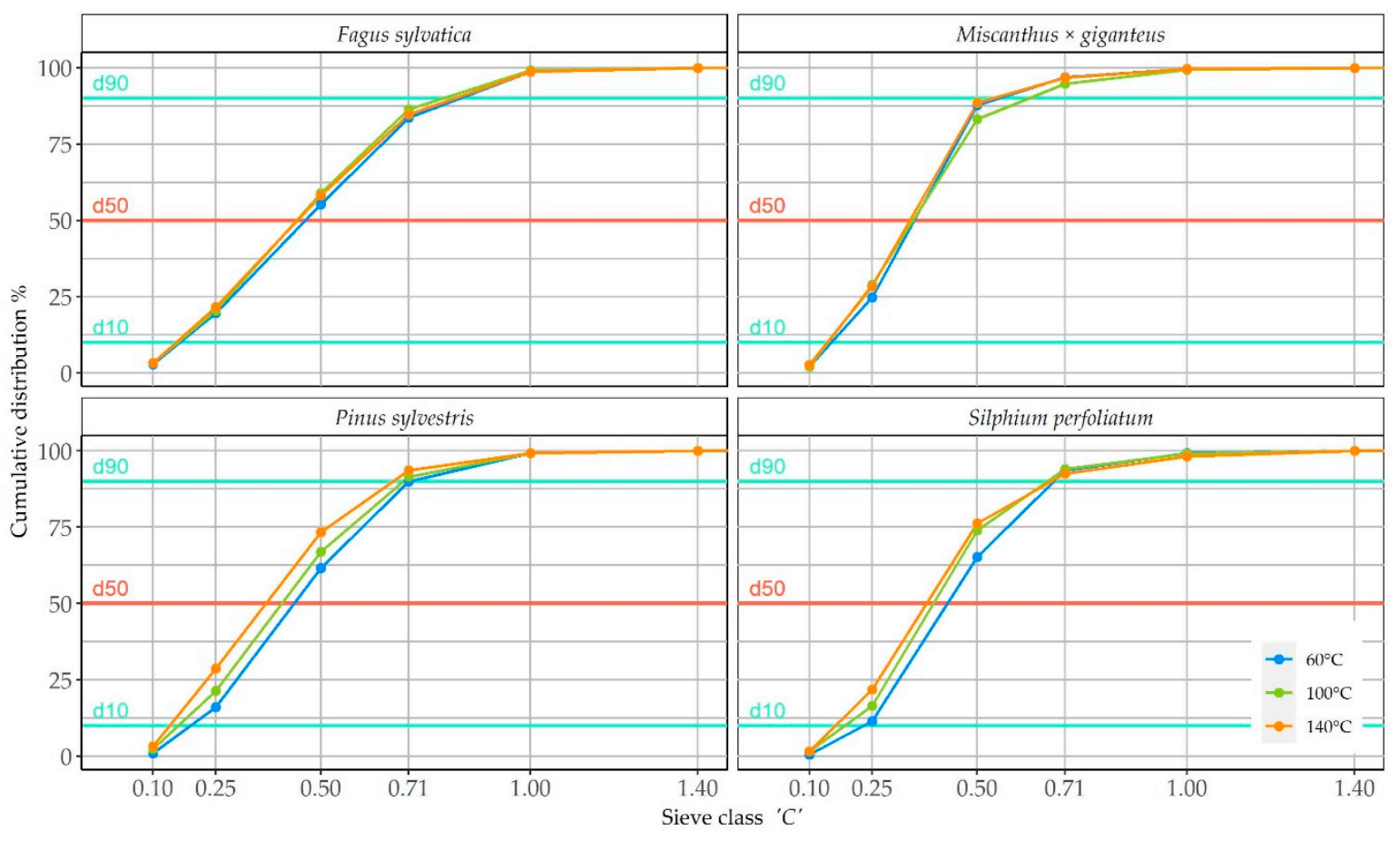

Figure 3. Cumulative particle size distribution (cPSD) raw materials ground with the knife milling system. 


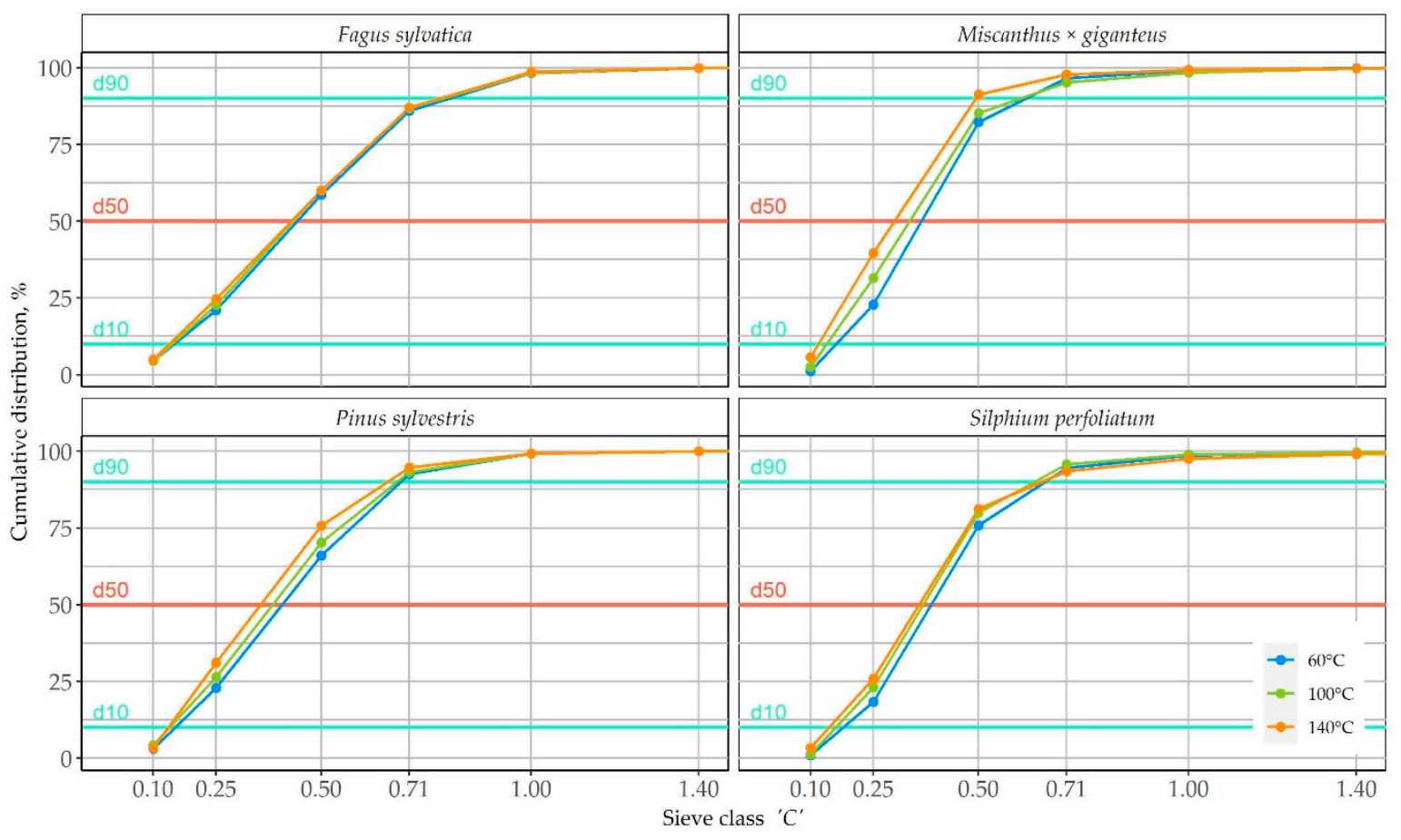

Figure 4. Cumulative particle size distribution (cPSD) raw materials ground with the hammer milling system.

Figure 5 presents a comparison of the $d_{50}$ analysis of all samples. In general, the lowest values of this parameter were for Miscanthus. This indicates that this material, during milling, produces the majority of fine particles (mean value of $d_{50}$ of all samples is $0.34 \mathrm{~mm}$ ). Slightly coarser particles would be obtained for Pinus and Silphium $\left(d_{50}-0.39 \mathrm{~mm}\right)$ and for Fagus $\left(d_{50}-0.44 \mathrm{~mm}\right)$. Comparing the milling systems in most cases, the sample ground on the hammer system had a lower $d_{50}$ compared to that milled on the knife system. The only exception was Miscanthus dried at $60{ }^{\circ} \mathrm{C}$, where the trend was reversed. A similar trend was observed by Kirsten et al. by studying grass (hay) grindability [72]. The greatest differences in $d_{50}$ values caused by the milling system type were observed for biomass dried at $60^{\circ} \mathrm{C}$. The increase in drying temperature resulted in a decrease between $d_{50}$ values. The exception was once again Miscanthus, this time dried at $140^{\circ} \mathrm{C}$. The influence of drying temperature on grindability is clear for Pinus, Silphium (independently of milling systems), and Miscanthus milled with a hammer system. Grindability increases ( $d_{50}$ value decrease) as the drying temperature increases. In other cases, the changes were less intense. Among the tested samples, the best grindability was recorded for Miscanthus dried at $140{ }^{\circ} \mathrm{C}$ and milled on the hammer system (value $d_{50}$ of $0.3 \mathrm{~mm}$ ). The worst was acquired for Fagus at $60^{\circ} \mathrm{C}$ with the knife system $\left(d_{50}\right.$ of $\left.0.46 \mathrm{~mm}\right)$. This can be explained by the origin of the biomass. Fagus is a hard wood material with high solid density $\left(0.66 \mathrm{~g} / \mathrm{cm}^{3}\right)$ and Miscanthus grass has a value of $0.37 \mathrm{~g} / \mathrm{cm}^{3}$. Pinus as a soft wood material has a grindability between Fagus and Miscanthus $\left(\mathrm{DE}=0.51 \mathrm{~g} / \mathrm{cm}^{3}\right)$. For these materials, the assumption that higher DE values causes a decrease in grindability is valid. In the case of Silphium, the grindability was at the Pinus level even though the DE was only $0.22 \mathrm{~g} / \mathrm{cm}^{3}$. Solid density of Sylphium was lower than the value for Miscanthus, which is why the grindability of these materials is not comparable. This is probably due to the structure of Sylphium, which has a light, spongy core inside that is not very susceptible to grinding. In the cases studied, the appropriate fineness was obtained, defined by the value of $d_{50}$, which is required for pellet production. It is recommended that it is $0.6-0.8 \mathrm{~mm}$ [84], $0.5-0.7 \mathrm{~mm}$ [85], or even $0.2-0.4 \mathrm{~mm}$ [77]. 


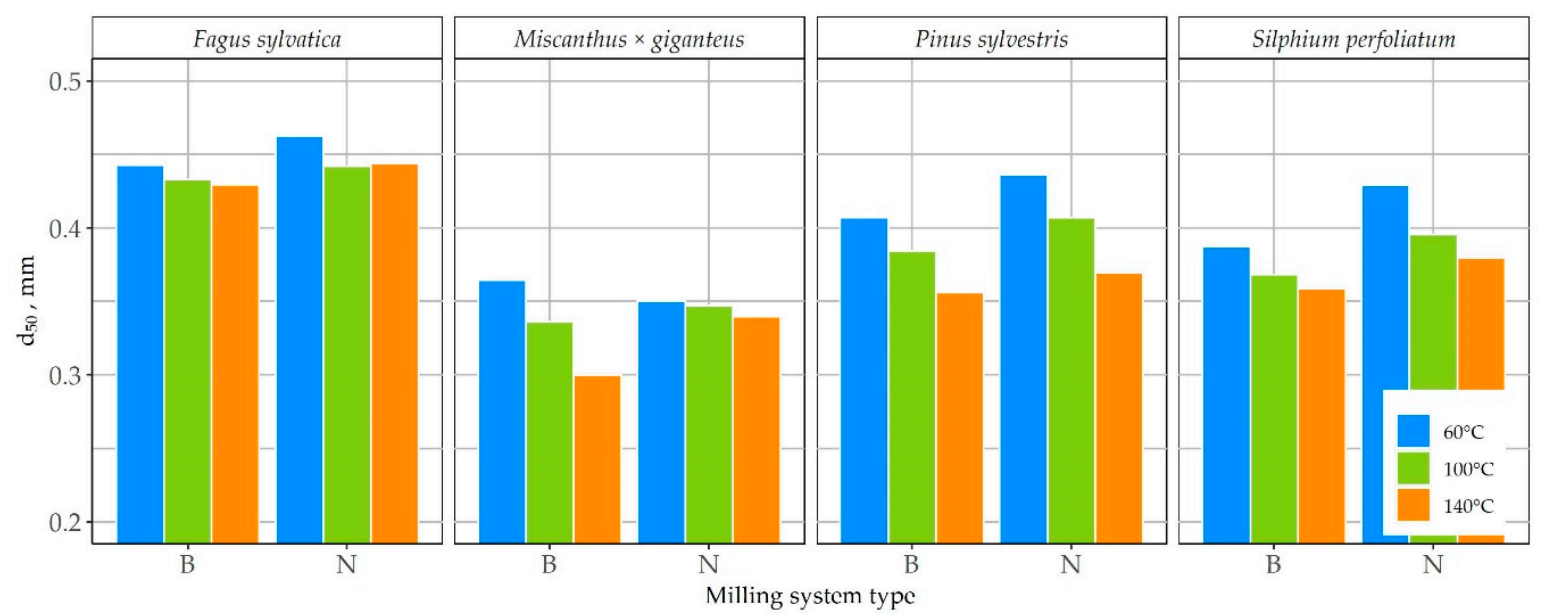

Figure 5. Ground materials' median value of particle size $d_{50}$, where B is the hammer milling system, and $\mathrm{N}$ is the knife milling system.

SPAN (Figure 6) is a very useful quantity when we want to take into account the changes in values of $d_{10}$ and $d_{90}$. The values obtained inform us on how broad the difference is in the dimensions of $80 \%$ of particles in the sample. A smaller value means a greater dimensional uniformity of the material. The Fagus is characterized by the highest SPAN values (average $0.65 \mathrm{~mm}$ ). Pinus and Silphium had values of $0.53 \mathrm{~mm}$ and $0.48 \mathrm{~mm}$, respectively, while Miscanthus had a value of $0.43 \mathrm{~mm}$. In our case, the woody biomass did not show dependence on the milling system as well as on temperature, with an exception for Fagus dried at $100{ }^{\circ} \mathrm{C}$ and milled on a knife system. In the case of Silphium, especially in the knife system, SPAN value increased with the drying temperature, which means that the uniformity of particle size decreases. The greatest variation was found in Miscanthus samples. The material dried at $100{ }^{\circ} \mathrm{C}$, the knife and hammer system, and the $60^{\circ} \mathrm{C}$ hammer system achieved a SPAN value of about $0.46 \mathrm{~mm}$, while the other variants achieved an average of $0.38 \mathrm{~mm}$. This information is important from the point of view of further use of the ground material. If the material is to be used for combustion or fertilizer purposes, its dimensional uniformity is important, so a minimum SPAN value [42,87]. In the case of the pressure compaction of biomass, dimensional homogeneity is not always recommended, and it is often stressed that in a decaying material there should be particles with a wide dimensional range so that large particles would form a skeleton of the agglomerate and its fine filling $[75,104,105]$. Therefore, it would be necessary to determine what SPAN value is optimal for biomass compaction processes and assess the ground material from this angle.

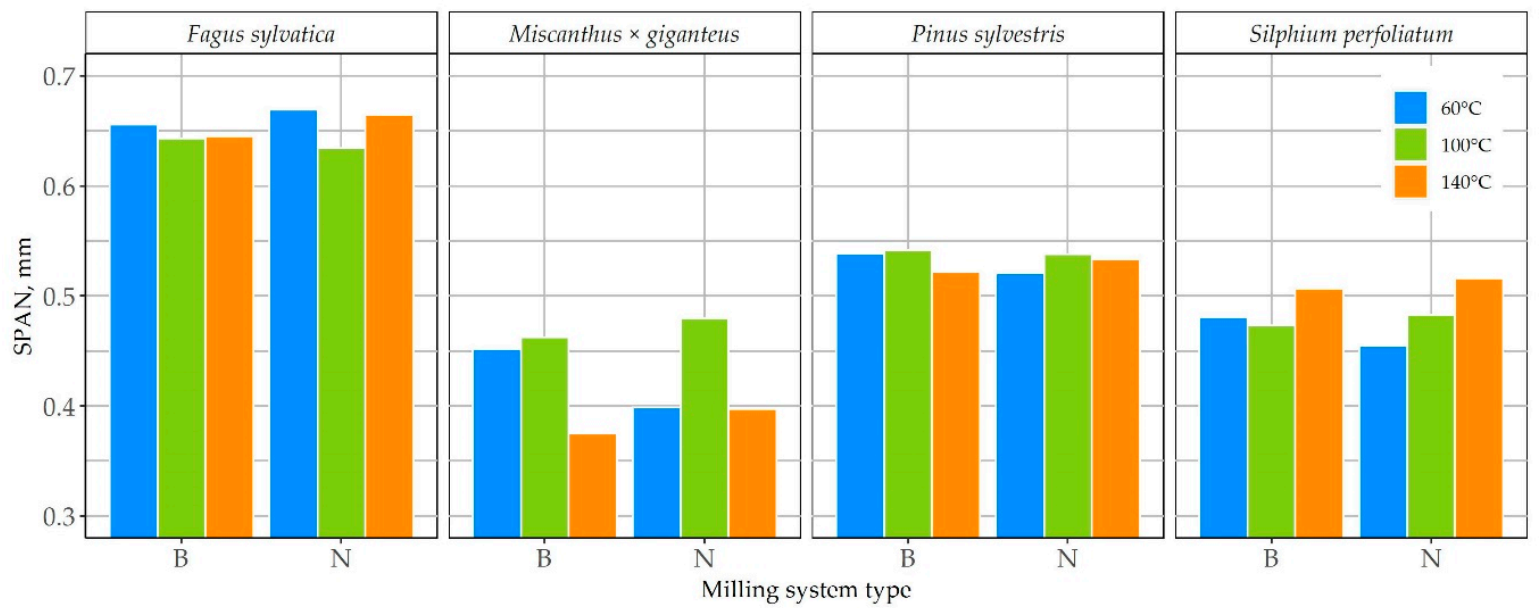

Figure 6. Ground materials' SPAN value, where B is the hammer milling system and N is the knife milling system. 
The SPAN does not carry information about the grinding process, only about the dimensional homogeneity in the sample. To take $d_{50}$ into account, rSPAN is used. The obtained values of this parameter are shown in Figure 7. If $d_{50}$ drops and SPAN is constant, the rSPAN rises (Pinus), as $d_{50}$ takes comparable values and SPAN rises, then rSPAN also rises (Miscanthus ground with knife system at 60 and $100{ }^{\circ} \mathrm{C}$ ). Therefore, due to the different nature of the change in $d_{50}$ and SPAN values, the resulting rSPAN does not give a clear indication of the change in particle size and homogeneity.

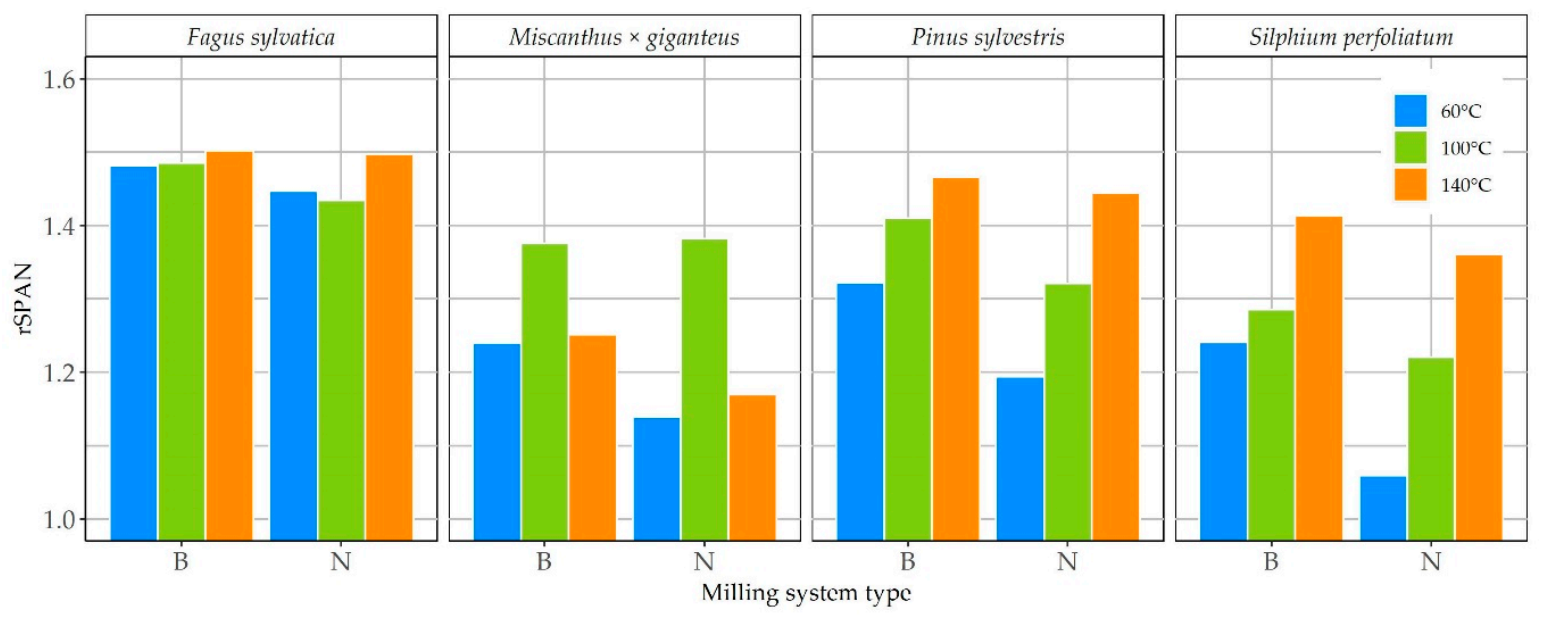

Figure 7. Ground materials' rSPAN value, where B is the hammer milling system and N is the knife milling system.

As none of the presented parameters gives clear feedback about milling quality, it is good way to provide a more complex form of data presentation. The $d_{50}, d_{10}$, and $d_{90}$ should be taken into account in this assessment. Therefore, we decided to present the results obtained by combining the SPAN with $d_{50}$ and the mean particle size (Figure 8) in an innovative way. The graph shows the value of SPAN (box height) and also contains information about the upper and lower dimensions of grain up to $d_{10}$ and $d_{90}$ from which it is calculated. Thanks to this, it is possible to compare the materials tested and also indicate which of them (despite the same SPAN value) had a larger or smaller grain size. The bars also contain information about the average grain size of $80 \%$ of the milled sample. Indication of the position of $d_{50}$ in relation to the average value indicates whether $50 \%$ of grains had a smaller or comparable size to $d_{a v g}$. Such a presentation of the results allows for unambiguous comparison of the tested materials and indicates which of them is characterized by better grindability. If we know the value of $d_{50}$ of the material before milling, we can determine the relative grain reduction. In the presented study, the initial $d_{50}$ of all materials was the same, so the relative grain reduction and $d_{50}$ carries similar information and was not presented in the paper.

By analyzing the grindability plot, it can be clearly stated that the most susceptible material to grinding was Miscanthus. The obtained values of $d_{50}$ were the lowest and the particles representing $80 \%$ of the deposit were in the narrowest dimensional range ( $\mathrm{d}$ from $0.12-0.62 \mathrm{~mm}$ ). The material least susceptible to grinding was Fagus, the $d_{50}$ of which was the highest out of the obtained and had the widest particle size range including particles with dimensions of about $0.14-0.83 \mathrm{~mm}$. The influence of the grinding system was insignificant, while the influence of temperature was most visible in the case of Pinus and Miscanthus. For Pinus, the $d_{50}$ value dropped as the temperature increased, while the SPAN changed slightly. In the case of Miscanthus, the value of $d_{50}$ decreased (hammer system) or remained unchanged (knife system), whereas the SPAN value clearly changed, reaching at least three variants (Figure 8). 


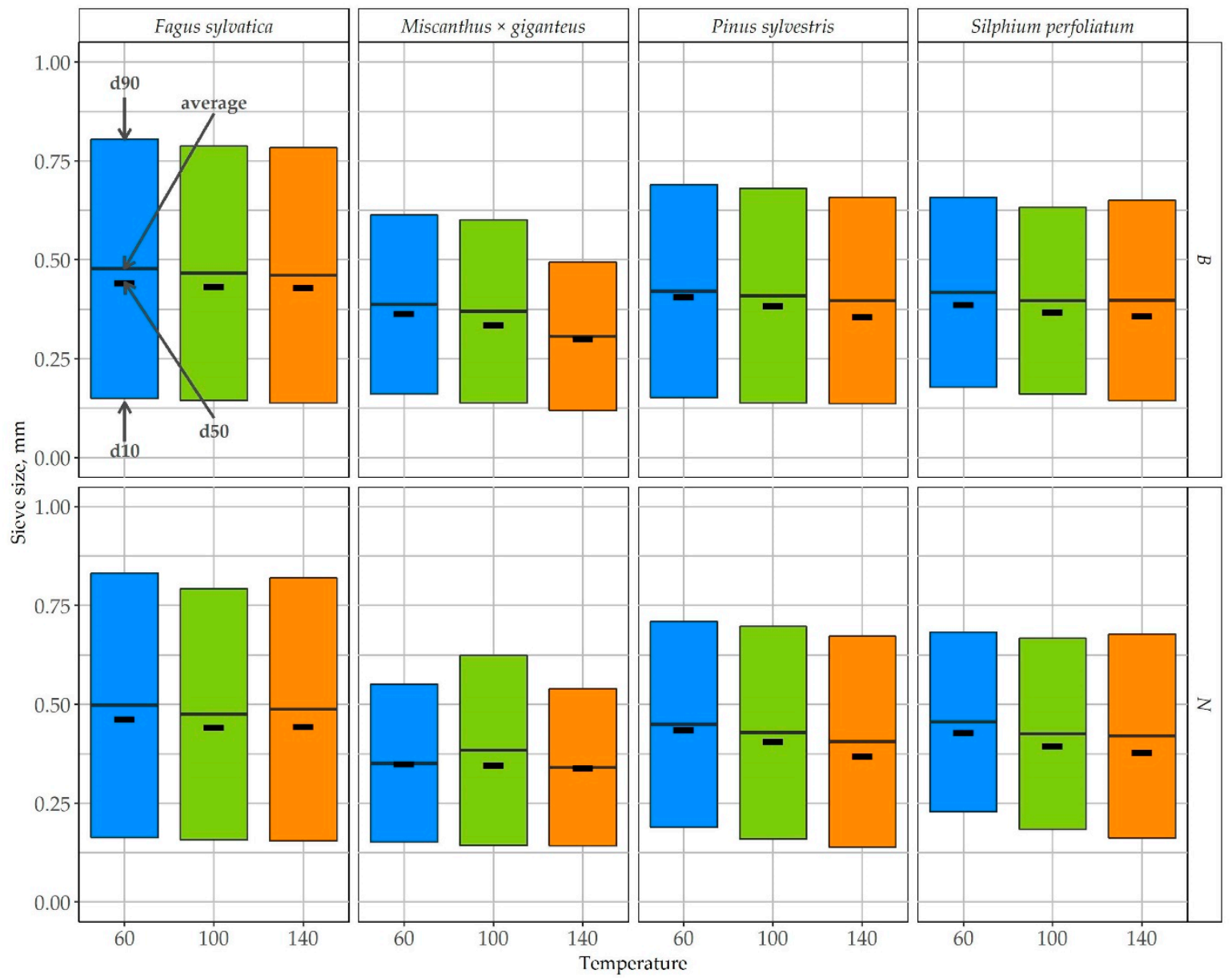

Figure 8. Grindability plot where B is the hammer milling system and $\mathrm{N}$ is the knife milling system.

\subsection{Grindability from the Aspect of Bulk Density Changes}

The changes in the bulk density (BD) is the second method used in the assessment of grindability. Figure 9 shows both $\mathrm{BD}$ of the material before and after grinding. It is noteworthy that although the PSD of a raw material is standardized, its BD changes, depending on the type of material and the drying temperature. Differences in BD values between materials were due to the difference in their specific densities. Comparing the changes within a given biomass type, it should be stated that in relation to the input material, the $\mathrm{BD}$ of the material after grinding always increased. This relation confirms that in the literature $[80,106]$. The highest increase was observed for Miscanthus, Fagus, and Silphium, and in the case of Pinus, the changes were insignificant. Only the Silphium biomass showed a clear dependency of $\mathrm{BD}$ to temperature. The increase in drying temperature caused an increase in BD. A comparison of the milling systems showed that the hammer system gives a material with slightly higher BD values compared to the knife system. The exception was for Silphium, where this dependence did not occur.

In general, higher values of $\mathrm{BD}$ are better, especially for the agglomeration process. High $\mathrm{BD}$ ensures the maximization of the number of contacts between the particles in which connections are formed during agglomeration [62,107]. Therefore, the measure of grindability is the BD value of the material after grinding. In this way, we can only compare the values of materials with the same specific density. In order to make this comparison independent of DE, we used bed packing density $\varphi$, and the obtained results are presented in Figure 10. The specific density of the tested materials changes the drying temperature, which is most probably the effect of temperature-induced shrinkage of the material. These changes are presented in Table 3. 

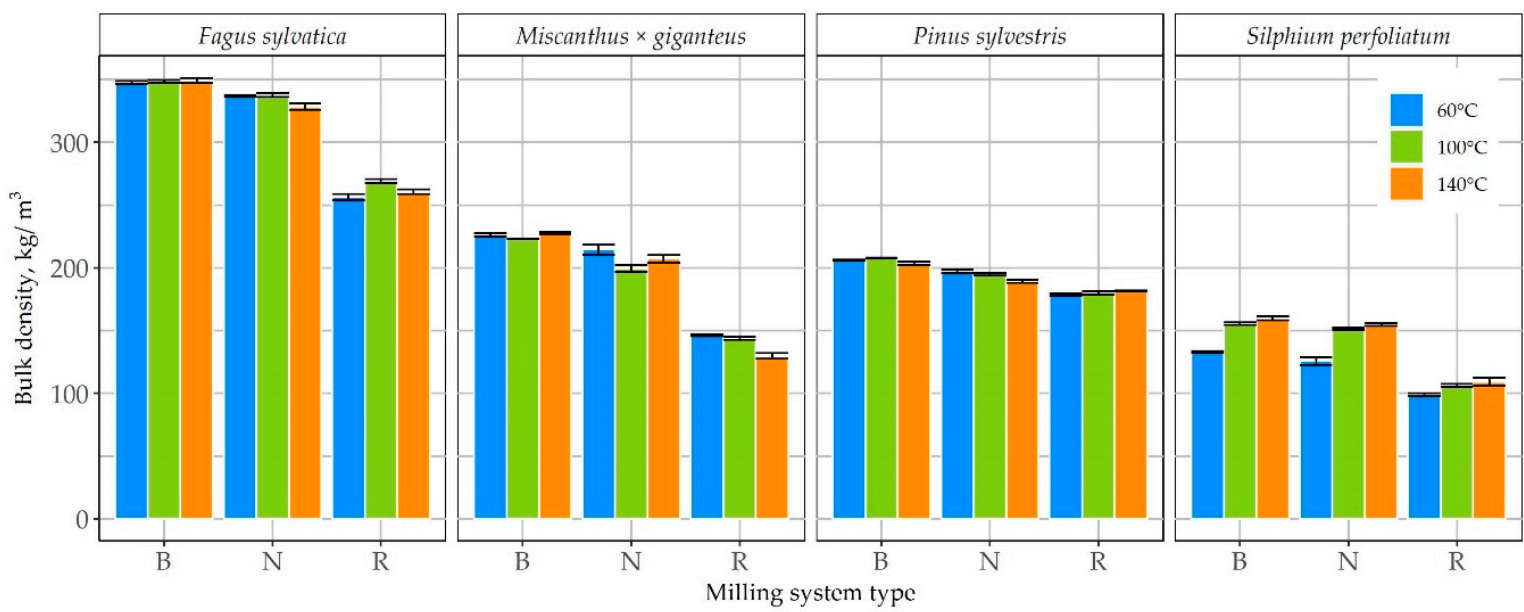

Figure 9. Bulk density changes in the material before and after grinding; $\mathrm{R}$ is the initial material, $\mathrm{B}$ is the hammer, and $\mathrm{N}$ is the knife grinding system.
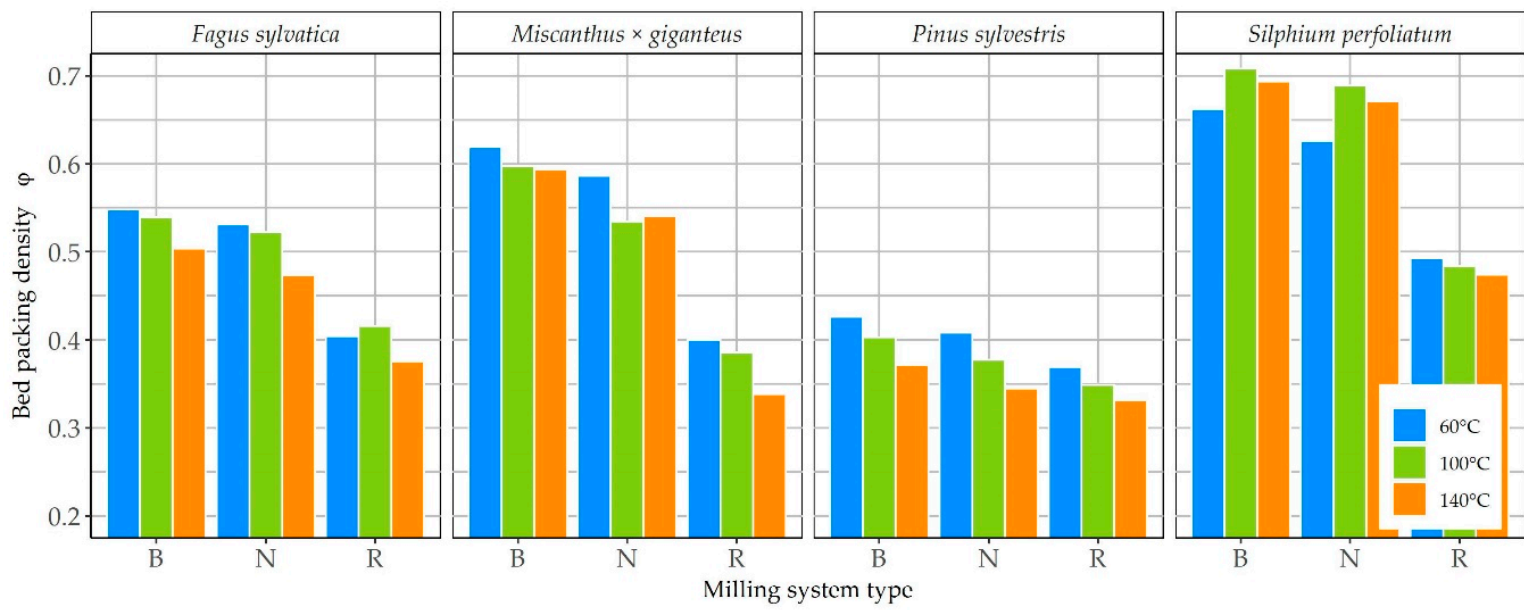

Figure 10. Packing density $\varphi$ changes in the material before and after grinding; $\mathrm{R}$ is the initial material, $\mathrm{B}$ is the hammer, and $\mathrm{N}$ is the knife grinding system.

Table 3. Raw material specific density DE $\left(\mathrm{g} / \mathrm{cm}^{3}\right)$.

\begin{tabular}{cccc}
\hline \multirow{2}{*}{ Raw Material } & \multicolumn{3}{c}{ Drying Temperature $\left({ }^{\circ} \mathbf{C}\right)$} \\
\cline { 2 - 4 } & $\mathbf{6 0}$ & $\mathbf{1 0 0}$ & $\mathbf{1 4 0}$ \\
\hline Fagus & 0.63 & 0.65 & 0.69 \\
Miscanthus & 0.36 & 0.37 & 0.38 \\
Pinus & 0.48 & 0.52 & 0.55 \\
Silphium & 0.2 & 0.22 & 0.23 \\
\hline
\end{tabular}

The results presented in Figure 10 gives more complex information than the crude bulk density. Comparing the tested materials, the highest $\varphi$ values were obtained for Silphium, followed by Miscanthus, Fagus, and the lowest was for Pinus. In most cases, the value decreased with the temperature, a different course is characteristic of Silphium biomass. The influence of the grinding system was insignificant, and the biggest differences were observed for Miscanthus.

The analysis of $\varphi$ allows us to indicate which of the tested variants is characterized by a high gesture of packing particles in the mass and which of them is not. Bed packing density is one of the factors that can be correlated with bed structure. Silphium (temperature $100{ }^{\circ} \mathrm{C}$, hammer system) had a value of $\varphi$ 0.71. This is close to the highest regular packing of identical balls in volume 
(hexagonal cubic packing, hcp) in which case, $\varphi$ is 0.74 [107-109]. On the other hand, the value obtained for random packing (rp) of identical balls was in the range of 0.57-0.68 [110]. In the case of Pinus, in the best variant, the $\varphi$ only reached 0.43 , which was lower than the above-mentioned values. The Fagus obtained a $\varphi$ reduced to lower values of the quoted range and Miscanthus shifted to upper values. Therefore, the wood biomass showed worse deposit filling parameters and the herbaceous biomass showed better vales. This may be caused by the shape of the particles forming the deposit. In the case of Miscanthus, and especially Sylphium, the spongy core is similar to a spherical one during grinding (Figure 11). In a mixture with elongated grains (originating from grinding rest part of steams), this resulted in better filling of the available space. In the case of wood biomass, the shape of all particles is elongated. As shown by Meng et al. [110], as the elongation of the deposit-forming particles increases, the value of $\varphi$ decreases

To specify the changes of $\varphi$ before and after grinding, it is necessary to specify the relative change of this parameter during grinding (Table 4). The results obtained clearly indicate that the best grindability determined by the relative $\varphi$ change was obtained for Miscanthus (values in the range of 28-43.4) and clearly the lowest by Pinus (4-13.3). The knife grinding system in each case caused a slight decrease in grindability compared to the hammer system. This may indicate that these grinding systems generate different particle shapes, which affects the relative $\varphi$ value. An analysis based on grindability plot, which takes into account only particle size, did not show differences between the grinding systems. Depending on the material and grinding system, the temperature had a different effect. In the case of Fagus, the lowest values were obtained for material dried at $100^{\circ} \mathrm{C}$. Pine grindability decreased with increasing drying temperature, while for Silphium, it increased.

Table 4. Biomass grindability defined as relative change of $\varphi$.

\begin{tabular}{cccccc}
\hline Grinding System & Temperature $\left({ }^{\circ} \mathbf{C}\right)$ & Fagus & Miscanthus & Pinus & Silphium \\
\hline \multirow{3}{*}{ hammer } & 60 & 26.2 & 35.4 & 13.3 & 25.6 \\
& 100 & 22.8 & 35.5 & 13.3 & 31.6 \\
& 140 & 25.4 & 43.4 & 10.8 & 31.6 \\
\hline \multirow{2}{*}{ knife } & 60 & 23.9 & 31.8 & 9.5 & 21.3 \\
& 100 & 20.4 & 27.9 & 7.5 & 29.7 \\
& 140 & 20.7 & 37.4 & 4.0 & 29.3 \\
\hline
\end{tabular}

The relative increase of $\varphi$, in this case, was a very good measure of grindability. It is based on the shape of the particles and changes in the arrangement in the material caused by milling. However, it does not give information about the degree of grain reduction, so the analysis of the grinding process should combine the grindability determination based on the analysis of PSD (proposed grindability plot) and $\varphi$ changes. Correlation of these two ways of describing grindability is not possible because PSD is based on changes in grain size without taking into account their shape, while $\varphi$ is based on the interconnection of grains of different shapes in space. 


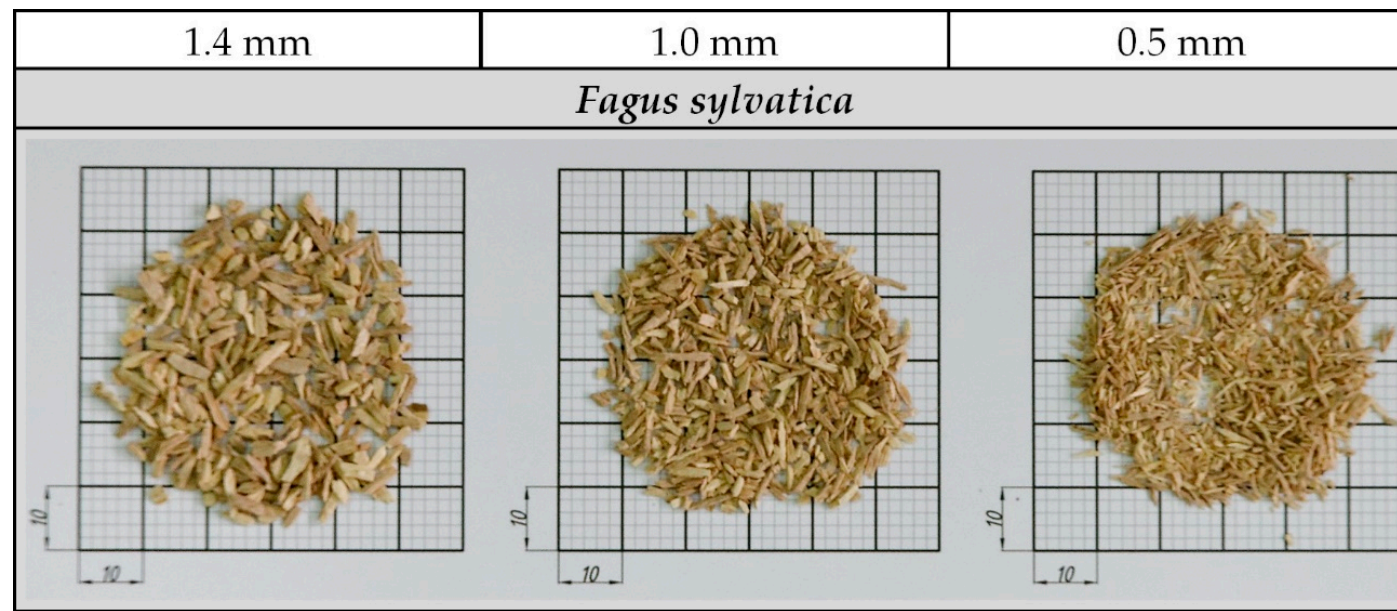

\section{Miscanthus $\times$ giganteus}

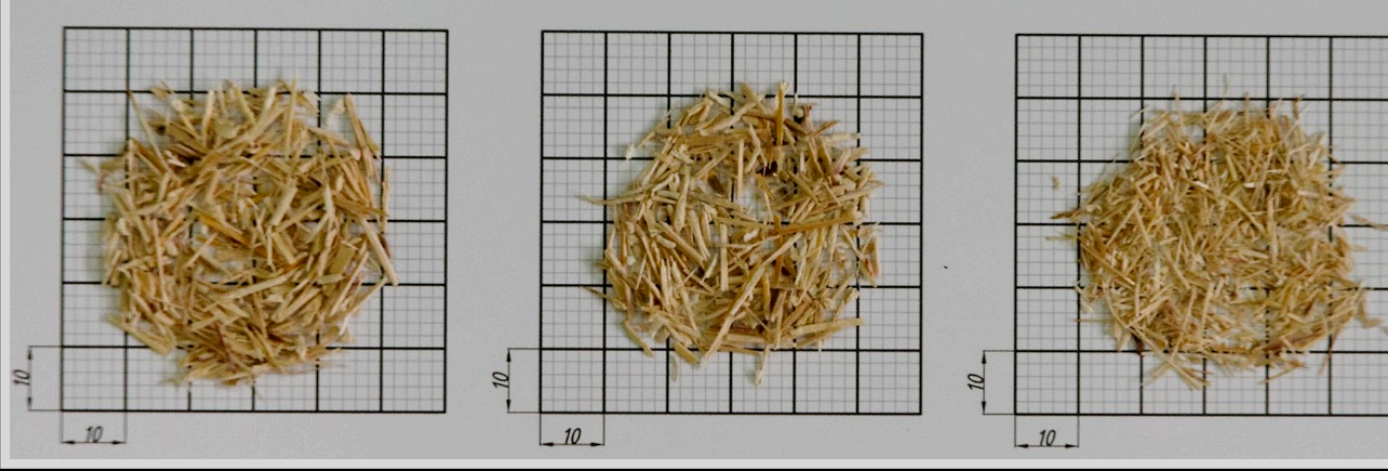

Pinus sylvestris

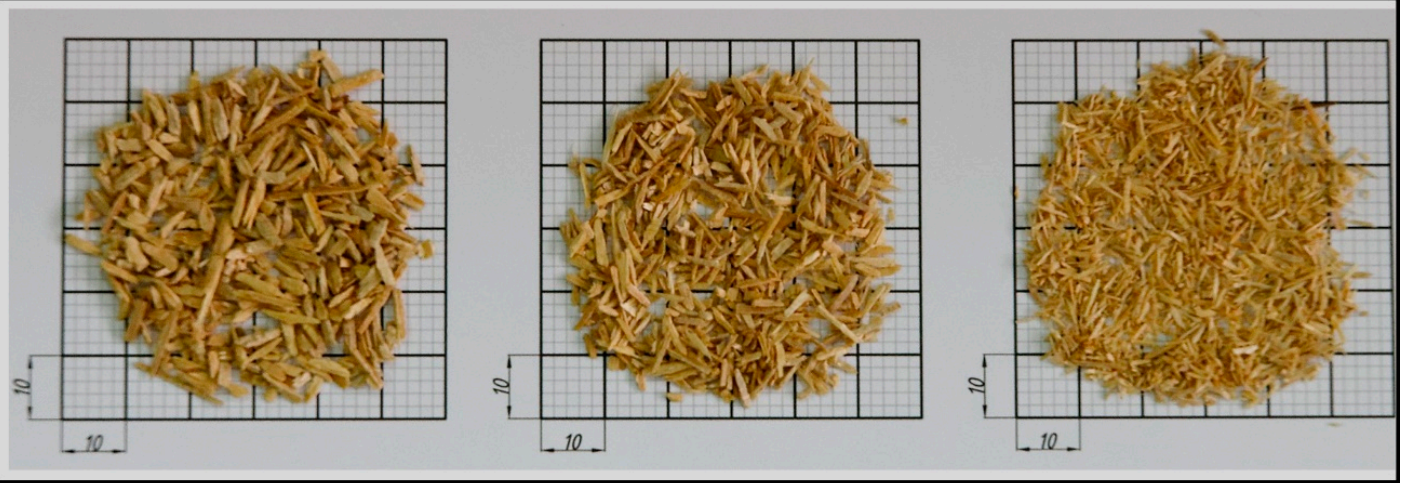

Silphium perfoliatum
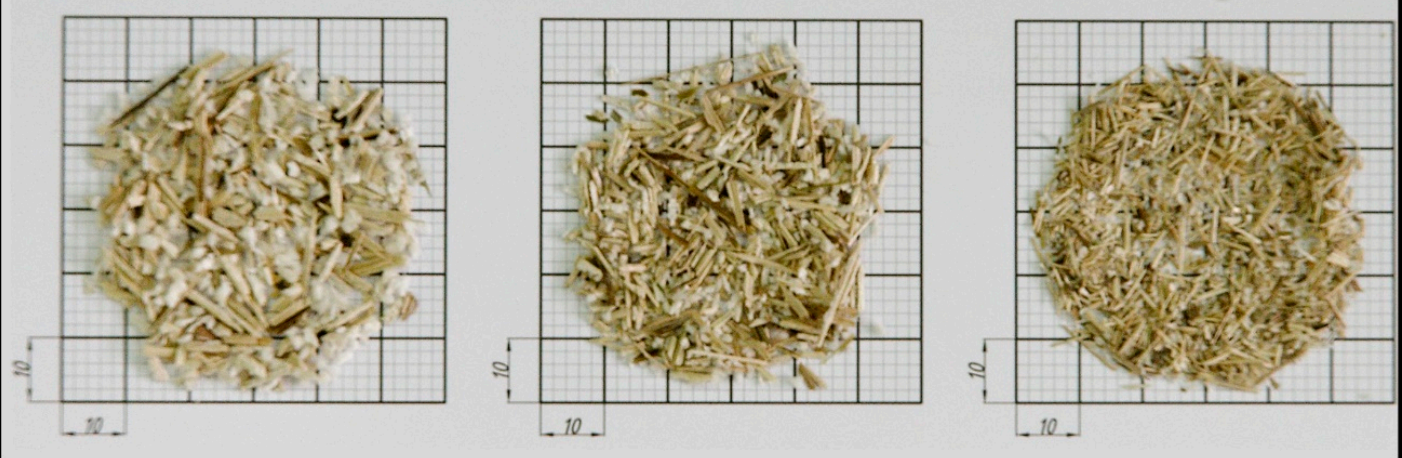

Figure 11. Shapes of the particle of the ground materials. 


\subsection{Grindability from the Aspect of Energy Demands}

The estimation of energy expenditure is important in assessing the profitability of technology. One of the key indicators is the net energy demand, which is the energy consumption of the process. Very often, the energy consumption is related to a unit of mass or volume. Analysis of the $E_{n e t . s}$ (Figure 12) indicates that the hammer system is more energy consuming. In any case, the increase in energy consumption compared to a knife system is at least twofold. The highest values were achieved for Miscanthus and Fagus. It is hard to determine any clear correlation of $E_{n e t . s}$ and drying temperature. In the case of the hammer system, we observed an upward trend for Fagus and a downward trend for Miscanthus. In other cases, the differences were not significant. In general, the lowest net energy demands were obtained for Silphium. For this type of biomass, $E_{\text {net.s }}$ was on a similar level within the milling system. At this stage, it is not possible to state the reason for these differences.
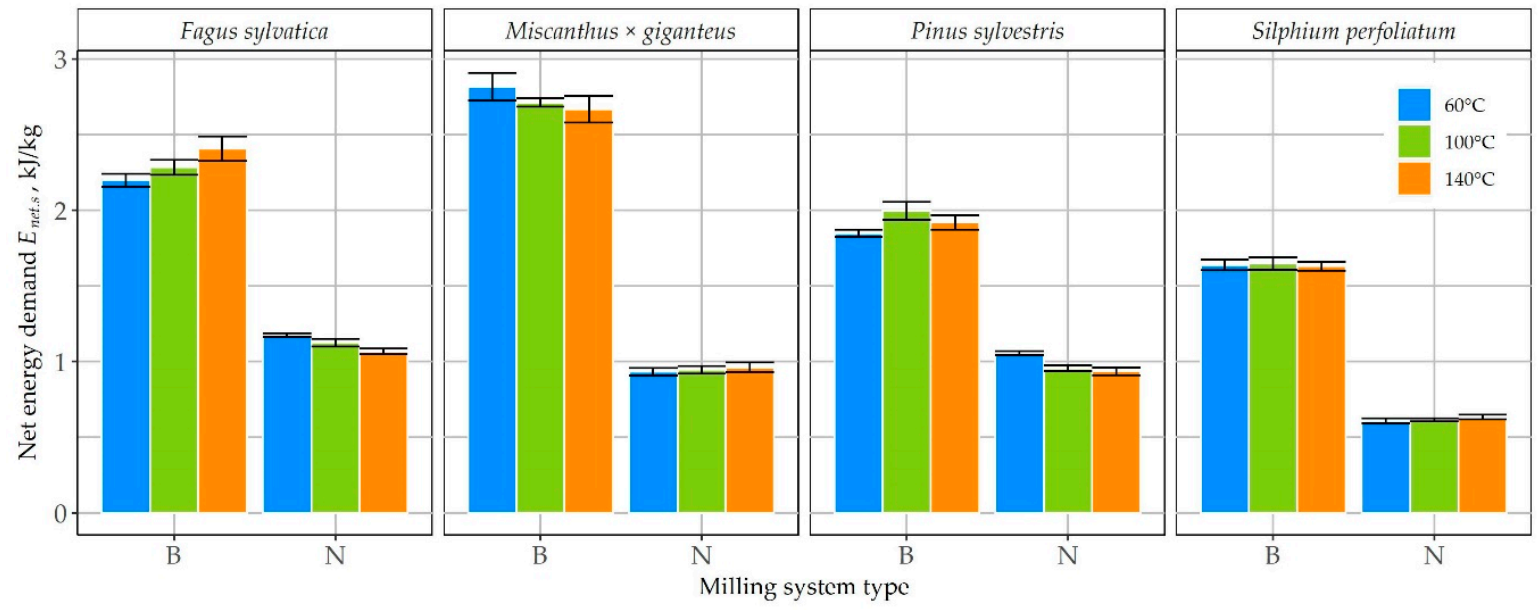

Figure 12. Values of net energy demands; $\mathrm{B}$ is the hammer and $\mathrm{N}$ is the knife grinding system.

The grindability criterion is more precise in energy demands analysis. It gives information on which part of energy was used to produce the finest particles. In general, this can be treated as milling efficiency. Figure 13 presents the $G_{0.25}$ in relation to the temperature and grinding system. As in the $E_{n e t . s}$ case, better results were obtained for the knife system. There were more visible relations with temperature. In all cases, an increase in drying temperature provided positive feedback to the $G_{0.25}$ factor. This shows that materials dried in high temperature are vulnerable to producing finer particles at output during milling. Furthermore, for Silphium, there was a very noticeable relation.
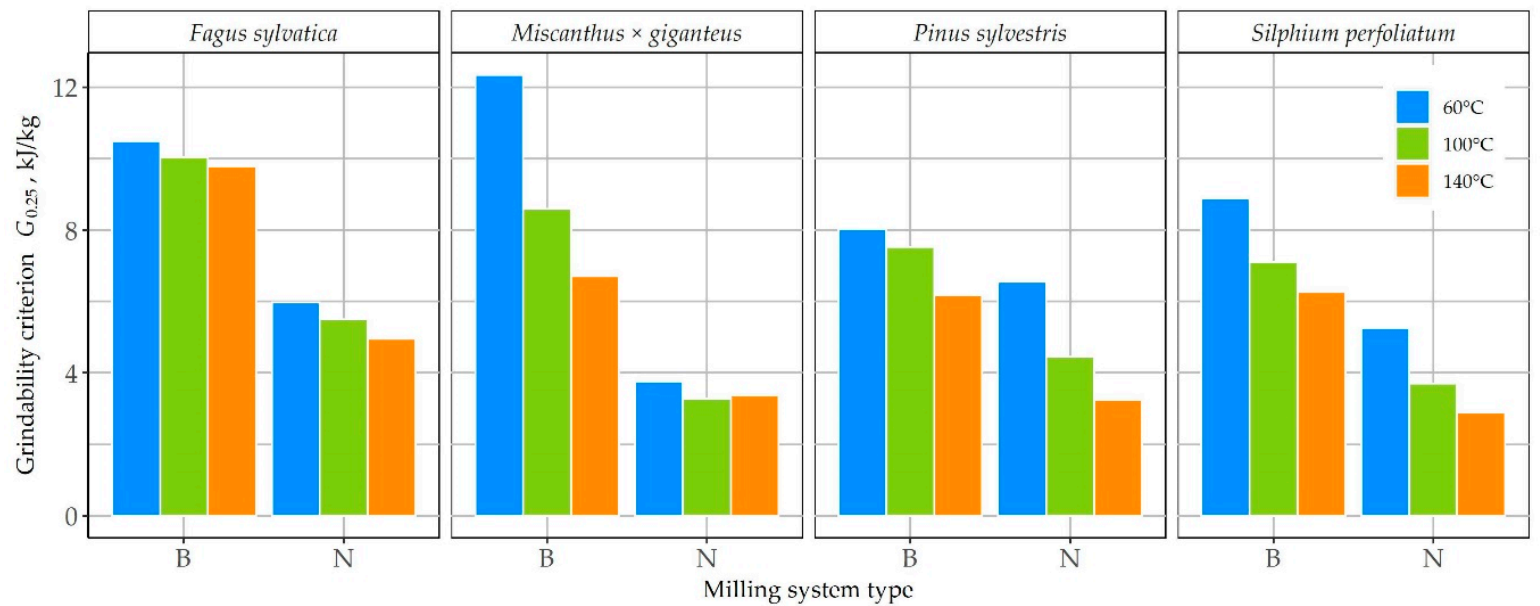

Figure 13. Values of grindability criterion; $\mathrm{B}$ is the hammer and $\mathrm{N}$ is the knife grinding system. 
Energy demands analysis is a very complex process, in which several factors need to be considered. In this case, the energy demands to mill $1 \mathrm{~kg}$ of material is not an unambiguous indicator, especially when we consider the grinding quality (PSD). The $G_{0.25}$ factor gives clear information about the effectiveness of the process. A steep change in this parameter for Miscanthus (hammer system) showed that there were some changes in structure during drying in high temperatures. These changes mainly affected friability, but in the case of the knife system such tendency was not visible.

As the $G_{0.25}$ factor was established for grain milling, doubts arise about the practical mining of it in the case of biomass. It is hard to compare these two processes, as flour usually needs to be ground to a very fine powder. Biomass used in conventional pulverized boilers should be fine (below $0.25 \mathrm{~mm}$ ) such as coal. On the other hand, there is solid biofuel production, where coarser fractions are required. This requires adaptation of the indicator to the technology needs. At this stage, it is not possible to develop such a dependency, and further research is needed.

\section{Conclusions}

The paper presents three different methods of determining biomass grindability. Standard particle size distribution analysis was extended to the form of the author's own graphical analysis. This method, in combination with the relative variability of bed packing density and grindability criterion, allowed us to make the following conclusions:

- The biomass origin affects the grindability. On the basis of the grindability plot, Miscanthus was the most susceptible to grinding and Fagus was the least. Analyzing the relative changes of Miscanthus $\varphi$ also showed the highest susceptibility, however, the Pinus biomass was the least vulnerable. In the case of $G_{0.25}$, the least effort should be made to grind Miscanthus with a knife system and the largest for Fagus with a hammer system (regardless of drying temperature). The exception was Miscanthus dried at $60^{\circ} \mathrm{C}$, which had the highest value of $G_{0.25}$ of all test variants

- Analyzing the influence of drying temperature, the grindability plot did not indicate any noticeable trends. The relative change of $\varphi$, clearly correlated with drying temperature. This effect is different with the material. For Miscanthus and Silphium, the grindability increased with the temperature, in contrast to Pinus. In the case of Fagus, the best grindability was characterized by a temperature of $100{ }^{\circ} \mathrm{C}$. Taking into account $G_{0.25}$, in each case, we observed a decrease in the input into the process as the drying temperature increased.

- The type of milling system, according to the grindability plot, had little influence on the course of the milling process (slightly better parameters can be obtained with a hammer system). The analysis of the relative values of $\varphi$ changes also allowed us to state that this system will cause larger changes, and thus the milling process evaluated according to this indicator is better than with the knife system. However, the analysis of the $G_{0.25}$ clearly shows that the knife system is up to twice as energy efficient.

For each material, the drying temperature was selected individually depending on the indicator that we wanted to obtain (e.g., Silphium dried at $60{ }^{\circ} \mathrm{C}$ obtained the best results according to the grindability plot, the greatest change of $\varphi$ occurred when the temperature exceeded $100{ }^{\circ} \mathrm{C}$, and the lowest energy consumption was characteristic of grinding this material dried at $140^{\circ} \mathrm{C}$ ). According to the grindability plot and the relative $\varphi$ change, the hammer system was slightly better, but the $G_{0.25}$ clearly indicates that the knife system was more energy efficient. The knife system was also connected with the greater susceptibility of this system to damage caused by foreign bodies in the form of stones or metal parts entering the mill.

The results in a broad and multi-aspect way describe the biomass grinding process assessed in terms of the achieved product parameters and energy consumption. Further research should focus on determining not only how the PSD, $\varphi$, or $G_{0.25}$ changes, but also what changes the grinding process should lead to. This means that the optimal PSD and BD of a given biomass type should be determined, depending on its use after the milling process (compaction or combustion). 
Author Contributions: Conceptualization, M.W., M.J., and S.S.; Methodology, M.W., M.J., and K.M.; Investigation, M.W., M.J., K.M., and S.S.; Resources, M.J. and K.M.; Data curation, M.J. and S.S.; Writing-original draft preparation, M.W. and M.J.; Writing—review and editing, M.W. and M.J.; Visualization, M.J.; Supervision, K.M. and S.S.; Formal analysis, M.J. and K.M. All authors have read and agreed to the published version of the manuscript.

Funding: This research was supported by the Ministry of Science and Higher Education of the Republic of Poland (Faculty of Production and Power Engineering, University of Agriculture in Krakow). Part of the studies presented were supported by the National Center of Research and Development (NCBR) Poland under the LIDER research program. Grant acronym BIOCARBON, with the title "Modern technology biomass torrefaction process to produce fuel mixtures, biocoal as additives for fertilizers, activated carbon for energy sector, agriculture, civil engineering and chemical industry", "LIDER IX” NCBR 2014-2020 (grant no. 0155/L-9/2017).

Conflicts of Interest: The authors declare no conflicts of interest.

\section{References}

1. EN ISO. 17225-1:2014 Solid Biofuels_Fuel Specifications and Classes_Part 1: General Requirements; International Organization for Standardization: Geneva, Switzerland, 2014.

2. Welker, C.; Balasubramanian, V.; Petti, C.; Rai, K.; DeBolt, S.; Mendu, V.; Welker, C.M.; Balasubramanian, V.K.; Petti, C.; Rai, K.M.; et al. Engineering Plant Biomass Lignin Content and Composition for Biofuels and Bioproducts. Energies 2015, 8, 7654-7676. [CrossRef]

3. Wróbel, M.; Jewiarz, M.; Mudryk, K.; Knapczyk, A. Influence of Raw Material Drying Temperature on the Scots Pine (Pinus sylvestris L.) Biomass Agglomeration Process-A Preliminary Study. Energies 2020, $13,1809$. [CrossRef]

4. Demirbaş, A. Estimating of structural composition of wood and non-wood biomass samples. Energy Sources 2005, 27, 761-767. [CrossRef]

5. Lamlom, S.H.; Savidge, R.A. A reassessment of carbon content in wood: Variation within and between 41 North American species. Biomass Bioenergy 2003, 25, 381-388. [CrossRef]

6. Szufa, S.; Wielgosiński, G.; Piersa, P.; Czerwińska, J.; Dzikuć, M.; Adrian, Ł.; Lewandowska, W.; Marczak, M. Torrefaction of Straw from Oats and Maize for Use as a Fuel and Additive to Organic Fertilizers-TGA Analysis, Kinetics as Products for Agricultural Purposes. Energies 2020, 13, 2064. [CrossRef]

7. Knapczyk, A.; Francik, S.; Wójcik, A.; Ślipek, Z. Application of Methods for Scheduling Tasks in the Production of Biofuels. In Renewable Energy Sources: Engineering, Technology, Innovation Springer Proceedings in Energy ICORES 2018; Wróbel, M., Jewiarz, M., Szlęk, A., Eds.; Springer: Cham, Switzerland, 2020; pp. 863-873, ISBN 978-3-030-13887-5.

8. Demirbas, A. Higher heating values of lignin types from wood and non-wood lignocellulosic biomasses. Energy Sources Part A Recovery Util. Environ. Eff. 2017, 39, 592-598. [CrossRef]

9. Dziurzyński, A. Zależności Między Wybranymi Właściwościami Fizycznymi Drewna Sosny i Buka a Zawartościa Jego Strukturalnych Składników Chemicznych; Wydawnictwo Akademii Rolniczej im. Augusta Cieszkowskiego: Poznań, Poland, 2003.

10. Bajpai, P. Pretreatment of Lignocellulosic Biomass for Biofuel Production; Springer: Cham, Switzerland, 2016; ISBN 978-981-10-0686-9.

11. Kaliyan, N.; Vance Morey, R. Factors affecting strength and durability of densified biomass products. Biomass Bioenergy 2009, 33, 337-359. [CrossRef]

12. Mendu, V.; Harman-Ware, A.E.; Crocker, M.; Jae, J.; Stork, J.; Morton, S.; Placido, A.; Huber, G.; Debolt, S. Identification and thermochemical analysis of high-lignin feedstocks for biofuel and biochemical production. Biotechnol. Biofuels 2011, 4, 43. [CrossRef]

13. Van Dam, J.E.G.; van den Oever, M.J.A.; Teunissen, W.; Keijsers, E.R.P.; Peralta, A.G. Process for production of high density/high performance binderless boards from whole coconut husk: Part 1: Lignin as intrinsic thermosetting binder resin. Ind. Crops Prod. 2004, 19, 207-216. [CrossRef]

14. Głowacki, S.; Tulej, W.; Jaros, M.; Sojak, M.; Bryś, A.; Kędziora, R. Kinetics of Drying Silver Birch (Betula pendula Roth) as an Alternative Source of Energy. In Renewable Energy Sources: Engineering, Technology, Innovation. Springer Proceedings in Energy ICORES 2017; Mudryk, K., Werle, S., Eds.; Springer: Cham, Switzerland, 2018; pp. 433-442, ISBN 978-3-319-72370-9. 
15. Karbowniczak, A.; Hamerska, J.; Wróbel, M.; Jewiarz, M.; Nęcka, K. Evaluation of Selected Species of Woody Plants in Terms of Suitability for Energy Production. In Renewable Energy Sources: Engineering, Technology, Innovation. Springer Proceedings in Energy ICORES 2017; Mudryk, K., Werle, S., Eds.; Springer: Cham, Switzerland, 2018; pp. 735-742, ISBN 978-3-319-72370-9.

16. Telmo, C.; Lousada, J. Heating values of wood pellets from different species. Biomass Bioenergy 2011, 35, 2634-2639. [CrossRef]

17. Filbakk, T.; Jirjis, R.; Nurmi, J.; Høibø, O. The effect of bark content on quality parameters of Scots pine (Pinus sylvestris L.) pellets. Biomass Bioenergy 2011, 35, 3342-3349. [CrossRef]

18. Robbins, M.P.; Evans, G.; Valentine, J.; Donnison, I.S.; Allison, G.G. New opportunities for the exploitation of energy crops by thermochemical conversion in northern Europe and the UK. Prog. Energy Combust. Sci. 2012, 38, 138-155. [CrossRef]

19. Lewandowski, I.; Scurlock, J.M.O.; Lindvall, E.; Christou, M. The development and current status of perennial rhizomatous grasses as energy crops in the US and Europe. Biomass Bioenergy 2003, 25, 335-361. [CrossRef]

20. Burvall, J. Influence of harvest time and soil type on fuel quality in reed canary grass (Phalaris arundinacea L.). Biomass Bioenergy 1997, 12, 149-154. [CrossRef]

21. Koçar, G.; Civaş, N. An overview of biofuels from energy crops: Current status and future prospects. Renew. Sustain. Energy Rev. 2013, 28, 900-916. [CrossRef]

22. Bilandžija, N.; Krička, T.; Matin, A.; Leto, J.; Grubor, M. Effect of Harvest Season on the Fuel Properties of Sida hermaphrodita (L.) Rusby Biomass as Solid Biofuel. Energies 2018, 11, 3398. [CrossRef]

23. Šiaudinis, G.; Jasinskas, A.; Šarauskis, E.; Steponavičius, D.; Karčauskienė, D.; Liaudanskienė, I. The assessment of Virginia mallow (Sida hermaphrodita Rusby) and cup plant (Silphium perfoliatum L.) productivity, physico-mechanical properties and energy expenses. Energy 2015, 93, 606-612. [CrossRef]

24. Stolarski, M.J.; Śnieg, M.; Krzyżaniak, M.; Tworkowski, J.; Szczukowski, S.; Graban, Ł.; Lajszner, W. Short rotation coppices, grasses and other herbaceous crops: Biomass properties versus 26 genotypes and harvest time. Ind. Crops Prod. 2018, 119, 22-32. [CrossRef]

25. Francik, S.; Knapczyk, A.; Francik, R.; Ślipek, Z. Analysis of Possible Application of Olive Pomace as Biomass Source. In Renewable Energy Sources: Engineering, Technology, Innovation. Springer Proceedings in Energy ICORES 2017; Mudryk, K., Werle, S., Eds.; Springer: Cham, Switzerland, 2018; pp. 583-592. ISBN 978-3-319-72370-9.

26. Dołżyńska, M.; Obidziński, S.; Kowczyk-Sadowy, M.; Krasowska, M. Densification and Combustion of Cherry Stones. Energies 2019, 12, 3042. [CrossRef]

27. Obidziński, S.; Dołżyńska, M.; Kowczyk-Sadowy, M.; Jadwisieńczak, K.; Sobczak, P. Densification and Fuel Properties of Onion Husks. Energies 2019, 12, 4687. [CrossRef]

28. Davies, R. Ignition and Burning Rate of Water Hyacinth Briquettes. J. Sci. Res. Rep. 2013, 2, 111-120. [CrossRef] [PubMed]

29. Romanowska-Duda, Z.; Piotrowski, K.; Wolska, B.; Debowski, M.; Zielinski, M.; Dziugan, P.; Szufa, S. Stimulating Effect of Ash from Sorghum on the Growth of Lemnaceae-A New Source of Energy Biomass. In Renewable Energy Sources: Engineering, Technology, Innovation Springer Proceedings in Energy ICORES 2018; Wróbel, M., Jewiarz, M., Szlęk, A., Eds.; Springer: Cham, Switzerland, 2020; pp. 341-349. ISBN 978-3-030-13887-5.

30. Kubica, K.; Jewiarz, M.; Kubica, R.; Szlęk, A. Straw Combustion: Pilot and Laboratory Studies on a Straw-Fired Grate Boiler. Energy Fuels 2016, 30, 4405-4410. [CrossRef]

31. Francik, S.; Kurpaska, S. The Use of Artificial Neural Networks for Forecasting of Air Temperature inside a Heated Foil Tunnel. Sensors 2020, 20, 652. [CrossRef] [PubMed]

32. Niemczyk, M.; Kaliszewski, A.; Jewiarz, M.; Wróbel, M.; Mudryk, K. Productivity and biomass characteristics of selected poplar (Populus spp.) cultivars under the climatic conditions of northern Poland. Biomass Bioenergy 2018, 111, 46-51. [CrossRef]

33. Nielsen, H.K.; Lærke, P.E.; Liu, N.; Jørgensen, U. Sampling procedure in a willow plantation for estimation of moisture content. Biomass Bioenergy 2015, 78, 62-70. [CrossRef]

34. Bryś, A.; Bryś, J.; Głowacki, S.; Tulej, W.; Zajkowski, P.; Sojak, M. Analysis of Potential Related to Grass-Derived Biomass for Energetic Purposes. In Renewable Energy Sources: Engineering, Technology, Innovation; Springer: Cham, Switzerland, 2018; pp. 443-449. 
35. Knapczyk, A.; Francik, S.; Wójcik, A.; Bednarz, G. Influence of Storing Miscanthus x gigantheus on Its Mechanical and Energetic Properties. In Renewable Energy Sources: Engineering, Technology, Innovation; Springer: Cham, Switzerland, 2018; pp. 651-660.

36. Wróbel, M.; Mudryk, K.; Jewiarz, M.; Głowacki, S.; Tulej, W. Characterization of Selected Plant Species in Terms of Energetic Use. In Renewable Energy Sources: Engineering, Technology, Innovation. Springer Proceedings in Energy ICORES 2017; Mudryk, K., Werle, S., Eds.; Springer: Cham, Switzerland, 2018; pp. 671-681. ISBN 978-3-319-72370-9.

37. Bryś, A.; Zielińska, J.; Głowacki, S.; Tulej, W.; Bryś, J. Analysis of possibilities of using biomass from cherry and morello cherry stones for energy purposes. E3S Web Conf. 2020, 154, 01005. [CrossRef]

38. Hebda, T.; Brzychczyk, B.; Francik, S.; Pedryc, N. Evaluation of Suitability of Hazelnut Shell Energy for Production of Biofuels. In Proceedings of the Engineering for Rural Development, Jelgava, Latvia, 23-25 May 2018; Volume 17, pp. 1860-1865.

39. Stelte, W.; Sanadi, A.R.; Shang, L.; Holm, J.K.; Ahrenfeldt, J.; Henriksen, U.B. Recent developments in biomass pelletization-A review. BioResources 2012, 7, 4451-4490.

40. Larsson, S.H.; Thyrel, M.; Geladi, P.; Lestander, T.A. High quality biofuel pellet production from pre-compacted low density raw materials. Bioresour. Technol. 2008, 99, 7176-7182. [CrossRef]

41. Mandels, M.; Hontz, L.; Nystrom, J. Enzymatic hydrolysis of waste cellulose. Biotechnol. Bioeng. 1974, 16, 1471-1493. [CrossRef]

42. Tymoszuk, M.; Mroczek, K.; Kalisz, S.; Kubiczek, H. An investigation of biomass grindability. Energy 2019, 183, 116-126. [CrossRef]

43. Dyjakon, A.; Noszczyk, T. The Influence of Freezing Temperature Storage on the Mechanical Durability of Commercial Pellets from Biomass. Energies 2019, 12, 2627. [CrossRef]

44. Serrano, C.; Monedero, E.; Lapuerta, M.; Portero, H. Effect of moisture content, particle size and pine addition on quality parameters of barley straw pellets. Fuel Process. Technol. 2011, 92, 699-706. [CrossRef]

45. Tumuluru, J.S.; Wright, C.T.; Hess, J.R.; Kenney, K.L. A review of biomass densification systems to develop uniform feedstock commodities for bioenergy application. Biofuels Bioprod. Biorefining 2011, 5, 683-707. [CrossRef]

46. Styks, J.; Wróbel, M.; Frączek, J.; Knapczyk, A. Effect of Compaction Pressure and Moisture Content on Quality Parameters of Perennial Biomass Pellets. Energies 2020, 13, 1859. [CrossRef]

47. Kpalo, S.Y.; Zainuddin, M.F.; Manaf, L.A.; Roslan, A.M. A Review of Technical and Economic Aspects of Biomass Briquetting. Sustainability 2020, 12, 4609. [CrossRef]

48. Puig-Arnavat, M.; Shang, L.; Sárossy, Z.; Ahrenfeldt, J.; Henriksen, U.B. From a single pellet press to a bench scale pellet mill-Pelletizing six different biomass feedstocks. Fuel Process. Technol. 2016, 142, 27-33. [CrossRef]

49. Fagernäs, L.; Brammer, J.; Wilén, C.; Lauer, M.; Verhoeff, F. Drying of biomass for second generation synfuel production. Biomass Bioenergy 2010, 34, 1267-1277. [CrossRef]

50. Gebreegziabher, T.; Oyedun, A.O.; Hui, C.W. Optimum biomass drying for combustion-A modeling approach. Energy 2013, 53, 67-73. [CrossRef]

51. Ståhl, M.; Granström, K.; Berghel, J.; Renström, R. Industrial processes for biomass drying and their effects on the quality properties of wood pellets. Biomass Bioenergy 2004, 27, 621-628. [CrossRef]

52. Francik, S.; Łapczyńska-Kordon, B.; Francik, R.; Wójcik, A. Modeling and Simulation of Biomass Drying Using Artificial Neural Networks. In Renewable Energy Sources: Engineering, Technology, Innovation. Springer Proceedings in Energy ICORES 2017; Mudryk, K., Werle, S., Eds.; Springer: Cham, Switzerland, 2018; pp. 571-581, ISBN 978-3-319-72370-9.

53. Jones, J.M.; Saddawi, A.; Dooley, B.; Mitchell, E.J.S.; Werner, J.; Waldron, D.J.; Weatherstone, S.; Williams, A. Low temperature ignition of biomass. Fuel Process. Technol. 2015, 134, 372-377. [CrossRef]

54. Kumar, A.; Jones, D.; Hanna, M. Thermochemical Biomass Gasification: A Review of the Current Status of the Technology. Energies 2009, 2, 556-581. [CrossRef]

55. Jahirul, M.I.; Rasul, M.G.; Chowdhury, A.A.; Ashwath, N. Biofuels production through biomass pyrolysis-A technological review. Energies 2012, 5, 4952-5001. [CrossRef] 
56. Szufa, S.; Adrian, Ł.; Piersa, P.; Romanowska-Duda, Z.; Grzesik, M.; Cebula, A.; Kowalczyk, S. Experimental Studies on Energy Crops Torrefaction Process Using Batch Reactor to Estimate Torrefaction Temperature and Residence Time. In Renewable Energy Sources: Engineering, Technology, Innovation. Springer Proceedings in Energy ICORES 2017; Mudryk, K., Werle, S., Eds.; Springer: Cham, Switzerland, 2018; pp. 365-373. ISBN 978-3-319-72370-9.

57. Peng, J.H.; Bi, X.T.; Sokhansanj, S.; Lim, C.J. Torrefaction and densification of different species of softwood residues. Fuel 2013, 111, 411-421. [CrossRef]

58. Li, H.; Liu, X.; Legros, R.; Bi, X.T.; Jim Lim, C.; Sokhansanj, S. Pelletization of torrefied sawdust and properties of torrefied pellets. Appl. Energy 2012, 93, 680-685. [CrossRef]

59. Chandler, C.; Cheney, P.; Thomas, P.; Traband, L.D.W. Fire in Forestry-Vol.I. Forest Fire Behavior and Effects; John Wiley \& Sons: New York, NY, USA, 1983.

60. Chen, D.; Gao, A.; Cen, K.; Zhang, J.; Cao, X.; Ma, Z. Investigation of biomass torrefaction based on three major components: Hemicellulose, cellulose, and lignin. Energy Convers. Manag. 2018, 169, $228-237$. [CrossRef]

61. Stelte, W.; Holm, J.K.; Sanadi, A.R.; Barsberg, S.; Ahrenfeldt, J.; Henriksen, U.B. A study of bonding and failure mechanisms in fuel pellets from different biomass resources. Biomass Bioenergy 2011, 35, 910-918. [CrossRef]

62. Pietsch, W. Agglomeration Processes. Phenomena, Technologies, Equipment; Wiley-VCH Verlag GmBH.: Weinheim, Germany, 2002; ISBN 3-527-30369-3.

63. Wróbel, M.; Frączek, J.; Francik, S.; Ślipek, Z.; Mudryk, K. Modelling of Unit Contact Surface of Bean Seeds Using Artificial Neural Networks. In Proceedings of the Engineering for Rural Development, Jelgava, Latvia, 23-24 May 2013.

64. Wójcik, A.; Frączek, J.; Niemczewska-Wójcik, M. The relationship between static and kinetic friction for plant granular materials. Powder Technol. 2020, 361, 739-747. [CrossRef]

65. Wójcik, A.; Frączek, J.; Wota, A.K. The methodical aspects of the friction modeling of plant granular materials. Powder Technol. 2019, 344, 504-513. [CrossRef]

66. Mudryk, K.; Hutsol, T.; Wrobel, M.; Jewiarz, M.; Dziedzic, B. Determination of Friction Coefficients of Fast-Growing Tree Biomass. In Proceedings of the Engineering for Rural Development, Jelgava, Latvia, 22-24 May 2019; Volume 18.

67. Anukam, A.I.; Berghel, J.; Famewo, E.B.; Frodeson, S. Improving the Understanding of the Bonding Mechanism of Primary Components of Biomass Pellets through the Use of Advanced Analytical Instruments. J. Wood Chem. Technol. 2020, 40, 15-32. [CrossRef]

68. Rumpf, H. Particle Adhesion, Some Fundamential Aspects of the Selective Agglomeratin of Fine Coal. Agglomeration 1977, 77, 97-129.

69. EN ISO. 17827-1:2016 Solid Biofuels_Determination of Particle Size Distribution for Uncompressed Fuels—Part 1: Oscillating Screen Method Using Sieves with Apertures of $3.15 \mathrm{~mm}$ and Above; International Organization for Standardization: Geneva, Switzerland, 2016.

70. Mediavilla, I.; Fernández, M.J.; Esteban, L.S. Optimization of pelletisation and combustion in a boiler of 17.5 kWth for vine shoots and industrial cork residue. Fuel Process. Technol. 2009, 90, 621-628. [CrossRef]

71. Jewiarz, M.; Mudryk, K.; Wróbel, M.; Frączek, J.; Dziedzic, K. Parameters Affecting RDF-Based Pellet Quality. Energies 2020, 13, 910. [CrossRef]

72. Kirsten, C.; Lenz, V.; Schröder, H.W.; Repke, J.U. Hay pellets-The influence of particle size reduction on their physical-mechanical quality and energy demand during production. Fuel Process. Technol. 2016, 148, 163-174. [CrossRef]

73. Ivanyshyn, V.; Nedilska, U.; Khomina, V.; Klymyshena, R.; Hryhoriev, V.; Ovcharuk, O.; Hutsol, T.; Mudryk, K.; Jewiarz, M.; Wróbel, M.; et al. Prospects of Growing Miscanthus as Alternative Source of Biofuel. In Renewable Energy Sources: Engineering, Technology, Innovation. Springer Proceedings in Energy ICORES 2017; Mudryk, K., Werle, S., Eds.; Springer: Cham, Switzerland, 2018; pp. 801-812, ISBN 978-3-319-72370-9.

74. Wróbel, M. Assessment of Agglomeration Properties of Biomass_Preliminary Study. In Renewable Energy Sources: Engineering, Technology, Innovation Springer Proceedings in Energy ICORES 2018; Wróbel, M., Jewiarz, M., Szlęk, A., Eds.; Springer: Cham, Switzerland, 2020; pp. 411-418, ISBN 978-3-030-13887-5. 
75. Bergström, D.; Israelsson, S.; Öhman, M.; Dahlqvist, S.A.; Gref, R.; Boman, C.; Wästerlund, I. Effects of raw material particle size distribution on the characteristics of Scots pine sawdust fuel pellets. Fuel Process. Technol. 2008, 89, 1324-1329. [CrossRef]

76. Jannasch, R.; Quan, Y.; Samson, R. A Process and Energy Analysis of Pelletizing Switchgrass-Final Report Prepared for: Natural Resources Canada, Alternative Energy Division. Available online: https: //reap-canada.com/online_library/feedstock_biomass/11\%20A\%20Process.pdf (accessed on 1 June 2020).

77. Mani, S.; Tabil, L.G.; Sokhansanj, S. Effects of compressive force, particle size and moisture content on mechanical properties of biomass pellets from grasses. Biomass Bioenergy 2006, 30, 648-654. [CrossRef]

78. Relova, I.; Vignote, S.; Leon, M.A.; Ambrosio, Y. Optimisation of the manufacturing variables of sawdust pellets from the bark of Pinus caribaea Morelet: Particle size, moisture and pressure. Biomass Bioenergy 2009, 33, 1351-1357. [CrossRef]

79. Zafari, A.; Kianmehr, M.H. Factors affecting mechanical properties of biomass pellet from compost. Environ. Technol. 2014, 35, 478-486. [CrossRef]

80. Shaw, M.D.; Karunakaran, C.; Tabil, L.G. Physicochemical characteristics of densified untreated and steam exploded poplar wood and wheat straw grinds. Biosyst. Eng. 2009, 103, 198-207. [CrossRef]

81. Zawiślak, K.; Sobczak, P.; Kraszkiewicz, A.; Niedziółka, I.; Parafiniuk, S.; Kuna-Broniowska, I.; Tanaś, W.; Żukiewicz-Sobczak, W.; Obidziński, S. The use of lignocellulosic waste in the production of pellets for energy purposes. Renew. Energy 2020, 145, 997-1003. [CrossRef]

82. Stelte, W.; Holm, J.K.; Sanadi, A.R.; Barsberg, S.; Ahrenfeldt, J.; Henriksen, U.B. Fuel pellets from biomass: The importance of the pelletizing pressure and its dependency on the processing conditions. Fuel 2011, 90, 3285-3290. [CrossRef]

83. Kruszelnicka, W.; Kasner, R.; Bałdowska-Witos, P.; Flizikowski, J.; Tomporowski, A. The Integrated Energy Consumption Index for Energy Biomass Grinding Technology Assessment. Energies 2020, 13, 1417. [CrossRef]

84. Turner, R. Bottomline in feed processing: Achieving optimum pellet quality. Feed Manag. 1995, 46, 30-33.

85. Franke, M.; Rey, A. Improving Pellet Quality and Efficiency. Feed Technol. 2006, 10, 12-15.

86. Phanphanich, M.; Mani, S. Impact of torrefaction on the grindability and fuel characteristics of forest biomass. Bioresour. Technol. 2011, 102, 1246-1253. [CrossRef] [PubMed]

87. Bridgeman, T.G.; Jones, J.M.; Williams, A.; Waldron, D.J. An investigation of the grindability of two torrefied energy crops. Fuel 2010, 89, 3911-3918. [CrossRef]

88. Williams, O.; Eastwick, C.; Kingman, S.; Giddings, D.; Lormor, S.; Lester, E. Investigation into the applicability of Bond Work Index (BWI) and Hardgrove Grindability Index (HGI) tests for several biomasses compared to Colombian La Loma coal. Fuel 2015, 158, 379-387. [CrossRef]

89. Khalsa, J.; Leistner, D.; Weller, N.; Darvell, L.; Dooley, B. Torrefied Biomass Pellets-Comparing Grindability in Different Laboratory Mills. Energies 2016, 9, 794. [CrossRef]

90. Kanwal, S.; Munir, S.; Chaudhry, N.; Sana, H. Physicochemical characterization of Thar coal and torrefied corn cob. Energy Explor. Exploit. 2019, 37, 1286-1305. [CrossRef]

91. Arias, B.; Pevida, C.; Fermoso, J.; Plaza, M.G.; Rubiera, F.; Pis, J.J. Influence of torrefaction on the grindability and reactivity of woody biomass. Fuel Process. Technol. 2008, 89, 169-175. [CrossRef]

92. Repellin, V.; Govin, A.; Rolland, M.; Guyonnet, R. Energy requirement for fine grinding of torrefied wood. Biomass Bioenergy 2010, 34, 923-930. [CrossRef]

93. Mayer-Laigle, C.; Blanc, N.; Rajaonarivony, R.; Rouau, X. Comminution of Dry Lignocellulosic Biomass, a Review: Part I. From Fundamental Mechanisms to Milling Behaviour. Bioengineering 2018, 5, 41. [CrossRef] [PubMed]

94. Saleh, S.B.; Hansen, B.B.; Jensen, P.A.; Dam-Johansen, K. Influence of Biomass Chemical Properties on Torrefaction Characteristics. Energy Fuels 2013, 27, 7541-7548. [CrossRef]

95. Križan, P.; Matúš, M.; Šooš, L.; Beniak, J. Behavior of beech sawdust during densification into a solid biofuel. Energies 2015, 8, 6382-6398. [CrossRef]

96. Križan, P.; Šooš, L.; Matúš, M.; Beniak, J.; Svátek, M. Research of significant densification parameters influence on final briquettes quality. Wood Res. 2015, 60, 301-316.

97. Jewiarz, M.; Wróbel, M.; Fraczek, J.; Mudryk, K.; Dziedzic, K. Digestate, Ash and Trichoderm Based Fertilizer-Production Line Concept Design. MATEC Web Conf. 2018, 168. [CrossRef]

98. Francik, S.; Knapczyk, A.; Knapczyk, A.; Francik, R. Decision Support System for the Production of Miscanthus and Willow Briquettes. Energies 2020, 13, 1364. [CrossRef] 
99. EN ISO. 17827-2:2016 Solid Biofuels—Determination of Particle Size Distribution for Uncompressed Fuels—Part 2: Vibrating Screen Method Using Sieves with Aperture of $3.15 \mathrm{~mm}$ and Below; International Organization for Standardization: Geneva, Switzerland, 2016.

100. EN ISO. 17828:2015 Solid Biofuels-Determination of Bulk Density; International Organization for Standardization: Geneva, Switzerland, 2015.

101. Greffeuille, V.; Abecassis, J.; Barouh, N.; Villeneuve, P.; Mabille, F.; Bar L'Helgouac'h, C.; Lullien-Pellerin, V. Analysis of the milling reduction of bread wheat farina: Physical and biochemical characterisation. J. Cereal Sci. 2007, 45, 97-105. [CrossRef]

102. Dyankova, S.; Doneva, M.; Todorov, Y.; Terziyska, M. Determination of particle size distribution and analysis of a natural food supplement on pectin base. IOSR J. Pharm. 2016, 6, 1-8.

103. Sun, F.; Xu, B.; Zhang, Y.; Dai, S.; Yang, C.; Cui, X.; Shi, X.; Qiao, Y. Statistical modeling methods to analyze the impacts of multiunit process variability on critical quality attributes of Chinese herbal medicine tablets. Drug Des. Dev. Ther. 2016, 10, 3909-3924. [CrossRef]

104. Song, Y.; Tumuluru, J.; Iroba, K.L.; Tabil, L.G.; Xin, M.; Meda, V. Material and Operating Variables Affecting the Physical Quality of Biomass Briquettes. In Proceedings of the XVIIth World Congress of the International Commission of Agricultural and Biosystems Engineering (CIGR), Quebec City, QC, Canada, 13-17 June 2010.

105. Tumuluru, J. Effect of Moisture Content and Hammer Mill Screen Size on the Briquetting Characteristics of Woody and Herbaceous Biomass. KONA Powder Part. J. 2019, 36, 241-251. [CrossRef]

106. Frączek, J. (Ed.) Optymalizacja Procesu Produkcji Paliw Kompaktowych Wytwarzanych z Roślin Energetycznych; PTIR: Kraków, Poland, 2010; ISBN 978-83-930818-0-6.

107. Jin, W.; Jiao, Y.; Liu, L.; Yuan, Y.; Li, S. Dense crystalline packings of ellipsoids. Phys. Rev. E 2017, 95, 033003. [CrossRef] [PubMed]

108. Donev, A.; Cisse, I.; Sachs, D.; Variano, E.A.; Stillinger, F.H.; Connelly, R.; Torquato, S.; Chaikin, P.M. Improving the Density of Jammed Disordered Packings Using Ellipsoids. Science 2004, 303, 990-993. [CrossRef] [PubMed]

109. Donev, A.; Stillinger, F.H.; Chaikin, P.M.; Torquato, S. Unusually dense crystal packings of ellipsoids. Phys. Rev. Lett. 2004, 92, 255506. [CrossRef] [PubMed]

110. Meng, L.; Jiao, Y.; Li, S. Maximally dense random packings of spherocylinders. Powder Technol. 2016, 292, 176-185. [CrossRef] 